\title{
Financial Contagion Risk and the Stochastic Discount Factor
}

\author{
Louis Piccotti ${ }^{\mathrm{a}}$
}

This Draft: March 19, 2014

\begin{abstract}
This paper shows that financial contagion risk is an important source of the risk premium. Intermediaries' contribution to aggregate financial contagion is estimated in a new state space framework and a tradable financial contagion portfolio is formed. More contagious intermediaries earn excess returns over less contagious ones that cannot be explained by commonly used factor models. The relative performance of contagious intermediaries is also priced in the cross section of stock returns. Stocks that co-move more strongly with contagious intermediaries earn monotonically greater returns. These results are robust to factor model specification, test assets, and time period considered.
\end{abstract}

JEL Classification: C22, C58, G12, G14, G15, G21

Keywords: Asset pricing, Financial contagion, State-space modeling, Systemic risk

${ }^{a}$ Department of Finance, School of Business, University at Albany, The State University of New York, Albany, NY 12222, tel: +1-973-757-8256, e-mail: piccolr@gmail.com. All errors are my sole responsibility 


\title{
Financial Contagion Risk and the Stochastic Discount Factor
}

\begin{abstract}
This paper shows that financial contagion risk is an important source of the risk premium. Intermediaries' contribution to aggregate financial contagion is estimated in a new state space framework and a tradable financial contagion portfolio is formed. More contagious intermediaries earn excess returns over less contagious ones that cannot be explained by commonly used factor models. The relative performance of contagious intermediaries is also priced in the cross section of stock returns. Stocks that co-move more strongly with contagious intermediaries earn monotonically greater returns. These results are robust to factor model specification, test assets, and time period considered.
\end{abstract}


Financial intermediaries serve a special role in the economy through investing on households' behalf and by issuing credit which both can affect the aggregate consumption possibility set. As financial intermediaries experience negative shocks, household wealth decreases (Allen, Bali, and Tang (2012)) and credit may be constrained (Duchin, Ozbas, and Sensoy (2012) and Ivashina and Scharfstein (2010)). In the aggregate, consumption will be diminished. Conversely, as financial intermediaries experience positive shocks, household wealth increases and credit availability may be liberated and, in the aggregate, consumption increases. Financial intermediaries' propensity to experience positive and negative shocks contemporaneously will shock aggregate consumption possibilities in the same direction. Asset pricing theory proposes that risk-averse investors with concave utility will require a greater return on securities whose returns experience greater covariation with contagious intermediaries since these securities have high payoffs in good times and low payoffs in bad times.

Alternatively, since intermediaries serve as agents of households to invest on their behalf, it could be that intermediaries' marginal utility of wealth and stochastic discount factor (SDF) prices securities as proposed in the Cochrane (2011) presidential address. In the case of an intermediary SDF, increased financial contagion leads to increased interbank funding illiquidity, such as observed in Schnabl (2012). A severe enough decrease in funding liquidity can result in market freezes (Acharya, Gale, and Yorulmazer (2011)) or fire sales (Jotikasthira, Lundblad, and Ramadorai (2012) and Shleifer and Vishny (1992)). In each of these cases, for an intermediary with concave utility, asset payoffs will covary negatively with the intermediary's marginal utility of wealth. It follows that with an intermediary SDF, intermediaries will also require a greater expected return for holding securities that experience greater covariation with more contagious intermediaries.

This paper contributes to the new and growing area of financial intermediary asset pricing by showing that financial contagion risk enters the SDF. Financial contagion is defined in this paper as in Bekaert, et al. (2005) to be excess covariation in bank stock returns in excess of what is predicted by overall market movements. As an innovation to the contagion methodology literature, this paper scales excess bank return covariances by the return variance of the financial sector to give estimates of the contribution of each financial intermediary to total financial contagion as well as to provide an estimate of the fraction of the financial sector's return variance that is caused by financial 
contagion. High contagion intermediaries are found to outperform low contagion intermediaries, by an annualized mean return of 6.0 percent. Formal factor regressions show that the mean annualized abnormal return of the high contagion minus low contagion intermediary portfolio is 3.9 percent and persists after accounting for the three Fama and French (1993) factors, the Pástor and Stambaugh (2003) liquidity factor, and the Carhart (1997) momentum factor (hereafter, referred to as the FFCPS model). Additionally, a monotonic relationship cannot be rejected between intermediary portfolio contagion and intermediary portfolio mean return. Trend tests indicate that an increase in mean return of 80 basis points is required for investors to hold an adjacent intermediary decile with higher contagion risk.

The financial contagion risk factor portfolio (HCMLC) is formed by buying the decile of intermediary stocks that contribute the most to financial contagion and selling the decile of intermediary stocks that contribute the least to financial contagion. A monotonic relation between financial contagion beta and mean returns cannot be rejected. Investors require an increase in expected return of 40 basis points to hold an adjacent common stock decile with a higher financial contagion beta.

Asset pricing tests are used to test if financial contagion risk is priced in the cross section of stock returns. The price of the HCMLC factor is tested out of sample in the cross-section of firm level stock returns and test portfolios using the two-pass regression procedure of Fama and MacBeth (1973). Estimated annualized HCMLC risk premiums from Fama-MacBeth regressions are 5.4 percent in the cross-section of CRSP stocks when the CAPM is augmented with the financial contagion factor and 3.9 percent when the FFCPS model is augmented with the HCMLC factor. Significant HCMLC risk premiums are also obtained from Fama-MacBeth regressions using test portfolios sorted on size, book-to-market (B/M), momentum, and industry. Estimated Financial contagion risk premiums using these test portfolios generally range from 5 percent to 15 percent. Risk premium results are robust at the firm level and portfolio level to beta estimation window as well as time period considered in the Fama-MacBeth regressions. Pricing error tests further show that the HCMLC factor is at least as successful at pricing portfolios out of sample as the other factor models are and performs better than the CAPM and FF3F models at pricing the 49 industry portfolios, the $10 \mathrm{~B} / \mathrm{M}$ portfolios, and the 25 size-B/M plus 10 momentum portfolios. This out of sample pricing performance indicates that financial contagion risk is an important source of the risk 
premium. As a second test for risk-premiums, ex-post cross-sectional tests are used. Significant improvement in model fit is achieved by including the HCMLC factor. Whereas the FFCPS model obtains an adjusted $R^{2}$ of 0.665 in modeling sample mean returns of the ten size portfolios, including the HCMLC factor increases the adjusted $R^{2}$ to 0.889 .

The two papers that are most similar to this one are Adrian, Etula, and Muir (2012) and He and Krishnamurthy (2013). He and Krishnamurthy (2013) provides a theoretical basis for a financial intermediary SDF. Adrian, et al. (2012) empirically tests for an intermediary SDF. They find that a single-factor model, using broker-dealer leverage as the only factor, prices portfolios sorted on size, B/M, and momentum better than the Carhart four-factor model. The results in this paper provide evidence of an alternative and important avenue through which financial intermediary risk enters the SDF. While Adrian, et al. focus on intermediary leverage as a proxy for intermediary SDF, this paper focuses on how financial contagion risk enters the SDF. The intermediary-based factor in this paper has the advantage that it can be observed at any frequency while intermediary leverage observations are restricted to the quarterly frequency. This paper further adds to this literature by allowing financial intermediary returns to directly enter the SDF. Intermediary leverage and intermediary contagion need not be mutually exclusive, however. In the models of Allen and Gale (2000) and Leitner (2005), financial contagion results when interbank defaults occur in the presence of sufficiently high interbank leverage. On the other hand, financial contagion need not be correlated with intermediary leverage levels. Kyle and Xiong (2001) and Kodres and Pritsker (2002) develop models in which contagion can arise from a "flight to quality" by investors. Benmelech and Bergmann (2007) use the airline industry as a laboratory to show that contagion can alternatively arise from collateral values decreasing and increasing the cost of external finance for all participants in the industry. This paper adds to this literature financial contagion by showing that asset prices are importantly affected by contagion risks.

The remainder of this paper is organized as follows. Section I discusses the methodology used to estimate financial contagion. Section II discusses the data. Section III presents financial contagion estimates. Section IV and section V present the main asset pricing results. Section VI presents robustness tests. Section VII contains concluding remarks. 


\section{Financial Contagion Methodology}

Throughout this paper, the terms "bank", "financial intermediary", and "financial institution" are used interchangeably to mean the same thing. Financial contagion is defined to be the covariance term in the variance of the financial intermediary portfolio returns in excess of what is predicted by market movements. Identifying financial contagion is a three step procedure. In the first step, the component of observed bank returns that is generated by common market risk exposure is removed. Let there be $N$ stocks that make up the bank portfolio and assume that stock returns are generated by the following $k$-factor model

$$
\begin{aligned}
& r_{i, t}=\alpha_{i, t}+\boldsymbol{f}_{t}^{\prime} \boldsymbol{\beta}_{i, t}+e_{i, t}, \quad i \in\{1,2, \ldots, N\}, \quad t \in\left\{1,2, \ldots, T_{i}\right\} \\
& \boldsymbol{\beta}_{i, t}=\boldsymbol{\beta}_{i, t-1}+\boldsymbol{\eta}_{i, t}
\end{aligned}
$$

where $r_{i, t}$ is the observed stock return at time $t$ for bank $i, \boldsymbol{f}_{t}=\left(f_{1}, f_{2}, \ldots, f_{k}\right)_{t}^{\prime}$ is a vector of observed factors at time $t, \boldsymbol{\beta}_{i, t}=\left(\beta_{i, 1}, \beta_{i, 2}, \ldots, \beta_{i, k}\right)_{t}^{\prime}$ is the time varying vector of $k$ factor loadings, and $\alpha_{i, t}$ is a time-varying intercept term. $e_{i, t}$ is the bank-specific shock, which is orthogonal to the factors and is distributed $e_{i, t} \sim N\left(0, \sigma_{i, t}^{2}\right)$. The covariance matrix of residuals across financial institutions may not be diagonal. Non-diagonal elements that are not equal to zero represent contagious bank covariances. Equation (1), as it is written, allows the model parameter values to change over time. The transition equation of betas is given in eqn. (2). $\boldsymbol{\eta}_{i, t}$ is a vector of coefficient innovations with $e_{i, t}$ and $\boldsymbol{\eta}_{i, t}$ being uncorrelated. $\boldsymbol{\Sigma}_{i, \eta}$ is a $(k \times k)$ diagonal matrix containing the coefficient innovation variances. Using a diagonal matrix for $\boldsymbol{\Sigma}_{i, \eta}$ imposes that factor loadings follow a random walk. If $\boldsymbol{\Sigma}_{i, \eta}=\mathbf{0}$, then factor loadings are constant. The Kalman filter is used to recursively estimate the time varying regression coefficients. A detailed explanation of the Kalman filtering methodology can be found in Appendix A and Appendix B. Daily data is used to estimate eqns. (1) and (2) to capture within-month variation in factor loadings which Patton and Ramadorai (2013) show is important for modeling high-frequency risk exposure. Bank-specific shocks are the residual terms from eqn. (1)

$$
\widehat{e}_{i, t}=r_{i, t}-\mathbf{E}\left(r_{i, t} \mid \mathcal{F}_{t-1}\right)=r_{i, t}-\widehat{\alpha}_{i, t \mid t-1}-\boldsymbol{f}_{t}^{\prime} \widehat{\boldsymbol{\beta}}_{i, t \mid t-1}
$$


where $\mathbf{E}(\cdot)$ is the mathematical expectations operator and $\mathcal{F}_{t-1}$ is the information set available at time $t-1$.

In the second step, the estimated residuals from eqn. (3) are regressed, without an intercept term, on returns of the value-weighted bank portfolio

$$
\begin{aligned}
& \widehat{e}_{i, t}=z_{i, t} r_{I, t}^{(i)}+u_{i, t} \\
& z_{i, t}=z_{i, t-1}+\omega_{i, t}
\end{aligned}
$$

where $r_{I, t}^{(i)}$ is the return on the bank portfolio at time $t$. Bank $i$ 's return contribution to the total bank portfolio return must be excluded to prevent bank $i$ 's idiosyncratic shock variance from being identified erroneously as financial contagion. $z_{i, t}$ is the scalar regression coefficient at time $t$ for bank $i$. The $z_{i, t}$ coefficients are restricted to vary with time following a random walk and innovation $\omega_{i, t} \sim N\left(0, \Sigma_{i, \omega}\right)$. If $\Sigma_{i, \omega}=0$, then $z_{i, t}$ is constant across time. $z_{i, t}$ is allowed to be time varying to capture time varying financial contagion risk. $u_{i, t}$ is a random error term orthogonal to $\omega_{i, t}$ distributed as $u_{i, t} \sim N\left(\sigma_{u_{i}}^{2}\right)$. From eqn. (4) it is not possible to distinguish between causality leading from the bank portfolio to the bank-specific shock of bank $i$, from causality leading from bank $i$ 's idiosyncratic shock to the portfolio. Unbiased covariation is sufficient for this study and knowing direction of causality is not needed. The Kalman filtering methodology is used to estimate eqn. (4) equation-by-equation for all banks included in the sample. Resulting time-varying coefficients in eqn. (4) are filtered estimates of $z_{i, t}, \widehat{z}_{i, t \mid t}$, conditional on time $t$ information. Since $\widehat{e}_{i, t}$ is dependent on the coefficient estimates from eqn. (1), which are estimated with error, $\widehat{e}_{i, t}$ will contain measurement error. This measurement error will inflate the standard errors of $\widehat{z}_{i, t \mid t}$, but $\widehat{z}_{i, t \mid t}$ will continue to be an unbiased estimator of $z_{i, t}$. Unbiasedness is the only property required for this methodology.

The third step aggregates coefficient estimates from eqn. (4) across banks at each date. Since eqn. (4) is a linear model, the projection theorem shows that the estimator of $\widehat{z}_{i, t \mid t}$ is

$$
\widehat{z}_{i, t \mid t}=\frac{\mathbf{E}\left(\widehat{e}_{i, t} r_{I, t}^{(i)} \mid \mathcal{F}_{t}\right)}{\mathbf{E}\left(\left(r_{I, t}^{(i)}\right)^{2} \mid \mathcal{F}_{t}\right)}
$$


$\mathbf{E}\left(\left(r_{I, t}^{(i)}\right)^{2} \mid \mathcal{F}_{t}\right)=\sigma_{r_{I, t}^{(i)}}^{2}$ is the variance of bank portfolio returns at time $t$. Since $r_{I, t}^{(i)}=\sum_{j \neq i} w_{j, t} r_{j, t}=$ $\sum_{j \neq i} w_{j, t}\left(\alpha_{j, t}+\boldsymbol{f}_{t}^{\prime} \boldsymbol{\beta}_{j, t}+e_{j, t}\right)$ and the properties, $\mathbf{E}\left(\widehat{e}_{i, t} f_{l, t}\right)=0$ for all $i$ and $l \in[1, k]$, and $\mathbf{E}\left(\widehat{e}_{i, t} \alpha_{j, t}\right)=$ $0 \forall i, j$, it follows that

$$
\widehat{z}_{i, t \mid t}=\frac{\sum_{j \neq i} w_{j, t} \mathbf{E}\left(\widehat{e}_{i, t} e_{j, t}\right)}{\sigma_{r_{I}^{(i)}, t}^{2}}
$$

$w_{j}$ is the value weighting of bank $j$ in the bank portfolio. $\alpha_{j, t}, \boldsymbol{\beta}_{j, t}$, and $e_{j, t}$ are the true intercept, true factor loadings, and true firm-specific shock for stock $j$ at time $t$. Since plim $\widehat{e}_{i, t}=e_{i, t}$ and $\mathbf{E}\left(e_{i, t}\right)=0 \forall i, t, \mathbf{E}\left(\widehat{e}_{i, t} e_{j, t}\right)$ is an estimate of the covariance between $e_{i, t}$ and $e_{j, t}, \widehat{\mathbf{C V}}\left(e_{i, t}, e_{j, t}\right)$. Note that the $i$ 'th bank's contribution to the portfolio's return is held out in eqn. (4) causing $r_{I, t}^{(i)}$ to vary for a given time $t$ depending on which bank is the dependent variable. If, for all $i$, the $\widehat{z}_{i, t \mid t}$ estimates had common denominators, the fraction of portfolio variance due to contagion could be estimated by taking the weighted summation $\sum_{i} w_{i, t} \widehat{z}_{i, t \mid t}$. However, since $r_{I, t}^{(i)}$ is different for each $i$, each $\sigma_{r_{I}^{(i)}, t}^{2}$ will also be different. Therefore, $\widehat{z}_{i, t \mid t}$ must be post-multiplied by the variance ratio $\sigma_{r_{I}^{(i)}, t}^{2}\left(\sigma_{r_{I}, t}^{2}\right)^{-1}$ prior to the summation. $\sigma_{r_{I}, t}^{2}$ is the bank portfolio return variance, including all banks. Since $\sigma_{r_{I}^{(i)}, t}^{2}$ and $\sigma_{r_{I}, t}^{2}$ are unobservable and must be estimated, the following parsimonious 90-day rolling historical variance estimators are used

$$
\begin{aligned}
\widehat{\sigma}_{r_{I}^{(i)}, t}^{2} & =\frac{1}{89} \sum_{k=t-90}^{t-1}\left(r_{I, k}^{(i)}-\widehat{\mu}_{r_{I}^{(i)}, t}\right)^{2} \\
\widehat{\mu}_{r_{I}^{(i)}, t} & =\frac{1}{90} \sum_{k=t-90}^{t-1} r_{I, k}^{(i)} \\
\widehat{\sigma}_{r_{I}, t}^{2} & =\frac{1}{89} \sum_{t-90}^{t-1}\left(r_{I, k}-\widehat{\mu}_{r_{I}, t}\right)^{2} \\
\widehat{\mu}_{r_{I}, t} & =\frac{1}{90} \sum_{k=t-90}^{t-1} r_{I, k}
\end{aligned}
$$

where $r_{I, t}$ is the return on the complete bank portfolio (all bank stock returns included), $\widehat{\mu}_{r_{I}^{(i)}, t}$ is the mean return estimator for the hold out bank portfolio for the trailing 90 days, and $\widehat{\mu}_{r_{I}, t}$ is the mean return estimator for the complete bank portfolio for the trailing 90 days. A variance estimator using trailing observations is used rather than a centered variance estimator so that variances can be estimated with an investor's current information set. Admittedly, eqns. (7a)-(7d) are simple 
variance estimators. Since the ratio of variances is used, which is approximately equal to one, using a more sophisticated variance estimator will increase complexity while only adding marginal additional value.

Summing the product $w_{i, t} \widehat{z}_{i, t \mid t} \widehat{\sigma}_{r_{I}^{(i)}, t}^{2}\left(\widehat{\sigma}_{r_{I}, t}^{2}\right)^{-1}$ over all $i$ at each time $t$ yields

$$
\begin{aligned}
F C_{t} & =\sum_{i} w_{i, t} \widehat{z}_{i, t \mid t} \widehat{\sigma}_{r_{I}^{(i)}, t}^{2}\left(\widehat{\sigma}_{r_{I}, t}^{2}\right)^{-1}=\sum_{i} F C_{t}^{(i)}=\frac{2 \sum_{i, j: i<j} w_{i, t} w_{j, t} \widehat{\mathbf{C V}}\left(e_{i, t}, e_{j, t}\right)}{\widehat{\sigma}_{r_{I}, t}^{2}} \\
F C_{t} & =\frac{C}{A+B+C} \\
A & =\sum_{l=1}^{k} \widehat{\mathbf{V}}\left(f_{l, t}\right)\left(\sum_{i}\left(w_{i, t} \beta_{i, l, t}\right)^{2}+2 \sum_{i, j: i<j} w_{i, t} w_{j, t} \beta_{i, l, t} \beta_{j, l, t}\right) \\
B & =\sum_{i} w_{i, t}^{2} \widehat{\mathbf{V}}\left(e_{i, t}\right) \\
C & =2 \sum_{i, j: i<j} w_{i, t} w_{j, t} \widehat{\mathbf{C V}}\left(e_{i, t}, e_{j, t}\right)
\end{aligned}
$$

Eqn. (8) shows that at each time $t F C_{t}$ is an estimator of the fraction of bank portfolio return variance that is due to the covariances in bank-specific shocks, or financial contagion. Since $F C_{t}$ is a ratio, it will be bounded between -1 and +1 . The first term in the denominator of eqn. (8), A, is the contribution of common fundamental risks to the variance of the bank portfolio's return variance. If the entire variation of bank returns can be explained by the factor model, then $F C_{t}=0$. The second term of the denominator, $\mathrm{B}$, is the contribution that banks' idiosyncratic risks contribute to the overall bank portfolio's return variance. The third term in the denominator, C, is the effect that financial contagion has on the bank portfolio's return variance. $F C_{t}$ will only be non-zero if $\mathrm{C}$ is non-zero.

In the empirical results that follow, eqn. (1) is estimated with the Kalman filter within the market model framework presented below

$$
r_{i, t}=\alpha_{i, t}+\beta_{i, t} r_{m, t}+e_{i, t}
$$

where $r_{m, t}$ is the daily return on the market portfolio. Since other factors have little additional explanatory power at the daily frequency, using the market return as the only factor keeps the 
model parsimonious without a loss of generality. The residuals from the market model are then used as the dependent variable in eqn. (4) and eqn. (4) is estimated with the Kalman filter.

\section{Data and Summary Statistics}

Daily bank stock prices from January 1, 1960 to December 31, 2012 are obtained from the CRSP daily stock file. All domestic banks (SIC codes from 6000 to 6199 and share code 10 or 11) and broker/dealers (SIC codes from 6200 to 6299 and share code 10 or 11) are initially included in the

sample when their stock price first falls within a share price of $\$ 5$ and $\$ 1,000$. To avoid survivorship bias, once a financial stock enters the sample it remains in the sample, regardless of share price. Financial stocks are dropped from the sample, if and when they are dropped from CRSP. There are 2,388 banks in the sample with a total of 5,953,497 daily bank stock observations.

For asset pricing tests, all common stocks (CRSP share code 10 or 11) within the CRSP universe are collected at a monthly frequency from January 1968 to December 2011 from the CRSP monthly stock file. A stock enters the sample once it has a share price greater than $\$ 5$ and less than $\$ 1,000$. Once a stock enters the sample it remains in the sample, regardless of share price. It is removed from the sample if and when it is removed from CRSP to avoid survivorship bias. Daily financial stock returns are aggregated to monthly returns by converting daily returns into log returns, summing each month's log returns, and then converting the monthly aggregated log returns back into arithmetic returns by taking the exponential function of the aggregated log returns. Factor data is obtained for the same period at a monthly frequency from two sources. Fama and French's three factors, as well as the momentum factor, are obtained from Kenneth French's website and the tradable liquidity factor is obtained from Luboš Pástor's website. Asset pricing tests are constrained to the January 1968 to December 2011 period since that is the range of dates for which the tradable Pástor and Stambaugh liquidity factor portfolio is available.

\section{[ Insert Table I and Figure 1 about here ]}

Figure 1 plots the time series of the number of financial stocks that are contemporaneously included in the sample. Sample size increases from 10 financial institutions in 1960 to approximately 
1,000 in 1999. Thereafter, the sample size decreases to approximately 500 banks in 2012. Summary statistics for the sample of financial institutions and for estimated financial contagion are presented in panel A of Table I. Mean bank market value of equity (MVE) is $\$ 1.42$ billion with a standard deviation of $\$ 8.91$ billion. Median bank size is $\$ 0.08$ billion, providing evidence that the distribution

of bank size is heavily skewed to the right. Banks' contributions to financial contagion, $F C_{t}^{(i)}$, are also heavily skewed to the right. Whereas the maximum contribution to financial contagion is 3.9 basis points, the first and third quartiles are 0.0 and 0.8 basis points, respectively. The sample mean fraction of observed bank portfolio return variance caused by financial contagion, $F C_{t}$, is 17.9 percent and it has a sample standard deviation of 3.5 percent. $F C_{t}$ obtains a maximum of 27.5 percent and a minimum of 8.9 percent. Panel B presents summary statistics of the stock and factor return sample. Mean stock price is $\$ 24.81$, mean MVE is $\$ 1.22$ billion, and mean monthly trading volume is 6.7 million shares. Mean annualized returns on the MRKT, SMB, HML, MOM, LIQ and HCMLC portfolios are 6.0 percent, 1.2 percent, 4.8 percent, 9.6 percent, 6.0 percent, and 7.2 percent.

[ Insert Figure 2 about here ]

Figure 2 plots the level of the value-weighted bank index in the top panel, bank index return variance in the middle panel, and aggregate bank firm-specific shock covariances in the bottom panel. January 1, 1960 is used as the base year for index level and the base index level is set equal to one. Estimated bank-specific shock covariances display a countercyclical nature. Covariances are high in periods of market stress and close to zero in times of relative market tranquility. During the 2007-'09 financial crises, covariances between bank stocks unexplainable by market risk increased dramatically.

\section{Financial Contagion Estimates}

Figure 3 plots $F C_{t}$ estimates obtained from eqn. (8), the fraction of bank index return variance that is caused by financial contagion on a given day. Graphically, $F C_{t}$ scales the covariances in the bottom panel of Figure 2 by the variances in the middle panel of Figure $2 . F C_{t}$ is procyclical with 
increases in bank inter-connected occuring in good times and disentangling in bad times. Financial contagion is generally in the range of 11 percent to 16 percent from 1960 to 1985 . From 1985 to 2001 the level of financial contagion increases from 12.5 percent to 27 percent. During the 2007-2009 financial crises, $F C_{t}$ experienced a dramatic change in levels.

\section{[ Insert Figure 3 about here ]}

Figure 4 plots financial contagion, annotated with key corporate and policy events that occurred during the crisis period. The events included are: the failure of Bear Stearns, the emergency SEC naked short selling ban on a number of financial institutions, Lehman Brothers filing for chapter 11 bankruptcy protection, the bailout of American International Group (AIG), the passing of the Emergency Stabilization Act of 2008 into law by congress, the announcement of the troubled asset relief program (TARP), the announcement of the term asset-backed loan facility (TALF), the announcement of U.S. government subsidization of Bank of America, and the "Six Months of TARP" report. These events were chosen since they correspond most closely with sharp changes in financial contagion ${ }^{1}$.

\section{[ Insert Figure 4 about here ]}

Bear Stearns failing on March 14, 2008 was the first sign that financial institutions were in trouble. However, $F C_{t}$ increased only slightly on the news. Contagion rose less than 100 basis points on the news. A much larger revision to financial contagion occurred on July 15, 2008 when the SEC made an emergency order to ban naked short selling on a number of financial institutions that were perceived to pose a systemic risk. Financial contagion increased from 19.2 percent to 23.4 percent. This is the time that contagion was at its greatest during the crisis period. Lehman Brothers filed for chapter 11 bankruptcy protection on September 15, 2008. Contagion, however, was little affected by this event and had already been decreasing since the beginning of September. It would appear that the market largely expected the government to step in and prevent any other systemically important institutions from failing. AIG received an $\$ 85$ billion credit facility from the Federal Reserve the following day, on September 16, 2008. On October 3, 2008 the Emergency

\footnotetext{
${ }^{1}$ A more detailed timeline of the financial crisis can be seen on the St. Louis Federal Reserve's website.
} 
Stabilization Act of 2008 was passed by congress. This bill, which contained the troubled asset relief program (TARP), authorized the U.S. Treasury to spend up to $\$ 700$ billion to unfreeze credit markets. TARP was formally announced to the public on October 14, 2008. Market perceptions of financial contagion were dramatically impacted by these events. From September 16, 2008 to mid November 2008, financial contagion dropped from 21 percent to 9 percent. At this point, financial contagion expectations were at one of their lowest over the fifty-two year sample period.

Since the Lehman Brothers and AIG events are only separated by one day it is difficult to empirically identify which event was the primary source of the large reduction in contagion risk that followed. An argument in favor of the Lehman Brothers event could be that banks reduced their leverage, as is found in Adrian and Song (2014) (Figure 5, page 383), fearing that there would be no backstop by the government. Conversely, an argument in favor of the AIG event could be that traders viewed the government as having set up a backstop for systemically important institutions and as a result traders priced a lower contagion risk into the market.

Financial contagion sharply increased in the second half of November 2008, however, rising from the low of 9 percent to 13 percent. The term asset-backed securities loan facility (TALF) was announced on November 25, 2008 to support the issuance of asset-backed securities (ABS). Contagion fell mildly following this, until it increased sharply again in response to the January 16, 2009 announcement that the government would provide a package of guarantees, liquidity, and capital to Bank of America. From January 16, 2009 to February 2009, financial contagion increased from 13 percent to 19 percent. Market expectations of financial contagion risks were revised higher in response of the government's intervention. The last sharp increase in contagion perceptions occurred in response to the "Six Months of TARP" report on April 7, 2009. Intermediary contagion subsequently increased from 18 percent to 20 percent. 


\section{Financial Contagion Risk and Returns}

\section{A Financial Contagion Risk and Bank Returns}

Each month financial stocks are sorted into equally-weighted portfolios based on their previous month's average contribution to aggregate financial contagion, $\left(T_{m}\right)^{-1} \sum_{t=1}^{T_{m}} F C_{t}^{(i)}$. $T_{m}$ denotes the number of trading days in the month. Portfolio returns are observed the following month and then portfolios are re-sorted. Bank returns are trimmed at the 2.5 percent and the 97.5 percent levels prior to portfolio formation to mitigate the influence of extreme returns. Results are unchanged when bank returns are only trimmed at the 99 percent level. Equally-weighted contagion-sorted financial portfolios are used rather than value-weighted contagion-sorted financial portfolios in this paper since value-weighting the financial portfolios would lead to highly skewed portfolio holdings.

Table II presents return statistics for contagion sorted bank portfolios. Panel A presents mean returns, their Sharpe ratios, and mean market value of equity of stocks in each portfolio. Decile, quintile, and tercile sorting methods are presented for robustness. Mean annualized returns for the decile, quintile, and tercile of financial stocks most susceptible to financial contagion are 11.9 percent, 12.2 percent, and 11.2 percent, respectively. Mean annualized returns for the least contagious portfolios are 5.9 percent, 5.3 percent, and 5.5 percent, respectively. The differences between the high contagion portfolios and low contagion financial stock portfolios are 6.0 percent, 6.9 percent, and 5.7 percent for decile sorts, quintile sorts, and tercile sorts, respectively. Returns are significantly different from zero at the one percent level or better for each sorting method. This relative outperformance of the high contagion portfolio is indicative that investors holding more contagious banks require higher expected returns.

Figure 5 plots the log wealth process of a trading strategy, rebalanced monthly, that buys the highest contagion decile and sells the lowest contagion decile, denoted as the HCMLC portfolio. Log wealth processes of the excess market (MRKT), small-minus-big (SMB), high B/M minus low B/M (HML), momentum (MOM), and tradable liquidity (LIQ) portfolios are also plotted. \$1.00, initially invested in the HCMLC bank portfolio in January, 1968, grows to $\$ 8.48$ dollars by December, 2011. Over the same period, $\$ 1.00$ in the MRKT, SMB, HML, MOM, and LIQ portfolios grows to $\$ 5.35$, $\$ 2.00, \$ 5.96, \$ 23.79$, and $\$ 9.28$, respectively. 


\section{[ Insert Table II and Figure 5 about here ]}

Annualized Sharpe ratios for the long-short contagion portfolios are $0.430,0.588$, and 0.589 for decile, quintile and tercile sorts, respectively. These Sharpe ratios are roughly in line with the market Sharpe ratio of 0.560 (not reported) over the same period. The least contagious quintile of financial stocks has a negative Sharpe ratio because the annualized mean risk-free rate during the sample period was 5.319 percent. Mean MVE of financial stocks included in each portfolio are presented in the final column. Financial institutions in the most contagious portfolios are larger than those in the least contagious ones. Mean MVE in the most contagious portfolios are $\$ 8.303$, $\$ 4.490$, and $\$ 2.788$ billion for decile sorts, quintile sorts, and tercile sorts, respectively. Mean market caps in the least contagious portfolios are $\$ 0.273, \$ 0.155$, and $\$ 0.106$ billion for decile sorts, quintile sorts, and tercile sorts, respectively.

Panel B of Table II presents regression results from regressing financial contagion sorted bank portfolio excess returns on the Carhart (1997) 4-factor model, augmented with the Pástor and Stambaugh (2003) tradable liquidity factor (hereafter, referred to as the FFCPS model). Long-short contagion portfolio return alphas for decile, quintile, and tercile sorts are 3.9 percent, 4.5 percent, and 3.2 percent, respectively. Alphas from each of the sorting methods are significant at the five percent level or better. These significant alphas appear to be driven by the underperformance of the least contagious portfolios. Whereas abnormal returns are insignificantly different from zero for the most contagious portfolios, abnormal returns for the least contagious portfolios are -3.0 percent, -3.5 percent, and -3.4 percent for decile, quintile, and tercile sorts, respectively. Negative alphas for the least contagious portfolios are each significant at the five percent level or better. Long-short contagion portfolio returns obtain a heavily positive loading on the market factor, a negative loading on the SMB factor, and a positive loading on the HML factor. There is not a significant factor loading on the MOM or LIQ factors.

\section{[ Insert Table III about here ]}

Table III presents bank portfolio returns for each decile sorted on financial contagion risk and

tests for monotonicity of trend in portfolio returns. If financial contagion risk enters the SDF, then a monotonic trend should be observed between contagion risk decile and decile mean return. 
Panel A contains mean contagion portfolio returns in the first two rows and portfolio return alphas obtained from regressing returns on the FFCPS model in the final two rows. Mean portfolio returns generally trend higher from the least contagious portfolio to the most contagious portfolio. The least contagious intermediary portfolio has an expected return of 5.9 percent and the portfolio of most contagious intermediaries has an expected return of 11.9 percent. The difference between the two returns is significant at the one percent level. Portfolio return alphas display an upward trend as well. Annualized alphas for the least contagious bank portfolio and most contagious bank portfolio are -3.0 percent and 1.0 percent, respectively. The difference between the two alphas is statistically significant. The significant negative alphas of the three least contagious deciles shows that these banks are persistently overpriced since they serve as a hedge against contagion risk.

Panel B formally tests for monotonicity of trend in portfolio mean returns and alphas. Due to random sampling error, a purely monotonic trend is unlikely to be observed in practice. Two tests for monotonicity, one parametric and one non-parametric, are used to test if the null that there is no monotonic relationship between intermediary portfolio contagion risk and portfolio mean return can be rejected. The parametric test regresses mean portfolio returns and alphas, separately, on a constant and trend variable ranging from one to ten. This regression test has the convenient property of providing evidence as to how much additional expected return investors require to hold an adjacently more contagious portfolio of financial intermediaries. Kendall's tau measure of rank correlation is the non-parametric test ${ }^{2}$. Kendall's tau is a measure of similarity in decile ranking and mean return ranking. If the two rankings are sufficiently similar, then the null hypothesis of no monotonic relationship between portfolio financial contagion risk and portfolio mean returns is rejected. Monotonicity tests, using the regression test, are presented in columns one and two, for mean returns and alphas, respectively. Tests using Kendall's tau are presented in columns three and four for mean returns and alphas, respectively. Both tests reject the null hypothesis of no monotonic relationship at the one percent level for both portfolio mean returns and alphas. The trend coefficient in the regression test indicates that investors require an increase in expected return of 80 basis points to hold an adjacently more contagious portfolio of financial institutions.

\footnotetext{
${ }^{2}$ The interested reader is referred to Kendall (1938) for details on the test computation.
} 


\section{B Financial Contagion Risk and Stock Returns}

Stocks' exposure to financial contagion risk is estimated with the following univariate and multivariate regressions

$$
\begin{aligned}
r_{i, t}^{e}= & \beta_{i, 0}+\beta_{i, M R K T} r_{M R K T, t}+\beta_{i, H C M L C} r_{H C M L C, t}+\varepsilon_{i, t} \\
r_{i, t}^{e}= & \beta_{i, 0}+\beta_{i, M R K T} r_{M R K T, t}+\beta_{i, S M B} r_{S M B, t}+\beta_{i, H M L} r_{H M L, t} \\
& \quad+\beta_{i, M O M} r_{M O M, t}+\beta_{i, L I Q} r_{L I Q, t}+\beta_{i, H C M L C} r_{H C M L C, t}+\varepsilon_{i, t}
\end{aligned}
$$

$r_{i, t}^{e}$ is the excess return on stock $i, r_{M R K T, t}$ is the excess return on the market portfolio (MRKT), $r_{S M B, t}$ is the return on the small-minus-big portfolio (SMB), $r_{H M L, t}$ is the return on the high B/Mminus-low $\mathrm{B} / \mathrm{M}$ portfolio (HML), $r_{M O M, t}$ is the return on the winners-minus-losers momentum portfolio $(\mathrm{MOM}), r_{L I Q, t}$ is the return on the portfolio of stocks with highest liquidity beta minus the portfolio of stocks with lowest liquidity beta (LIQ), and $r_{H C M L C, t}$ is the return on the decile of most contagious bank stocks minus the return on the decile of least contagious bank stocks, denoted the HCMLC portfolio. Asset pricing results are unchanged if the HCMLC portfolio is formed using quintile or tercile sorts. Eqns. (10) and (11) are estimated in a rolling regression framework, using 60-months of return observations. Stocks are sorted into value-weighted deciles based on their time $t$ HCMLC beta and then portfolio returns are observed in time $t+1$.

Table IV presents the correlation matrix of factor portfolio returns. Correlations between returns on the HCMLC portfolio, returns on the VIX (VIX), and changes in aggregate corporate default risk (DEF, defined as the log change in the log difference between yields on Baa and Aaa rated bonds) are included to test if the HCMLC portfolio simply captures changing aggreagate volatility risk or changing aggregate default risk. HCMLC returns are most correlated with the MRKT portfolio at 0.49 and least correlated with the SMB portfolio at -0.15. The correlations between HCMLC and DEF and between HCMLC and VIX are 0.111 and -0.344, respectively. These low correlation magnitudes indicate that financial contagion risk is a separate risk from aggregate volatility risk and aggregate default risk. HCMLC's correlations with the other factors are negative and close to zero. 
[ Insert Table IV and Table V about here ]

Table $\mathrm{V}$ presents returns from HCMLC beta sorted stock portfolio returns. Stock portfolio returns sorted on financial contagion beta from the univariate regression in eqn. (10) and their t-statistics are presented in the first two rows of Panel A. The lowest decile has an annualized mean return of 3.3 percent and the highest decile earns a mean return of 7.1 percent. The difference is not statistically significant. Generally, there is a positive relationship between contagion beta and expected return. Panel B presents the results from regressing portfolio mean returns on a constant and trend variable extending from one to ten to test the null hypothesis of no monotonic trend in portfolio mean returns. Results of this test are presented in column one. The null is rejected in favor of portfolios with greater financial contagion beta requiring a higher expected return. The regression trend coefficient indicates that investors require an additional 40 basis points in expected return to hold an adjacent portfolio with greater financial contagion beta. Kendall's tau in column three of Panel B agrees with the regression trend test. The monotonicity tests provide evidence that the difference in mean returns between the highest and lowest contagion beta deciles results from sampling error in the extreme portfolios.

Mean portfolio returns and t-statistics for portfolios sorted on financial contagion betas obtained from the multivariate regression in eqn. (11) are presented in the final two rows of Panel A. Similar to the univariate case, there is generally a positive relationship between contagion beta and expected returns. The lowest decile has a mean return of 5.3 percent and the highest decile has a mean return of 6.9 percent. Both the regression trend test and Kendall's tau reject the null hypothesis of no monotonic relationship between mean portfolio return and financial contagion beta at the five percent level or better. Again, the regression trend test indicates that investors require an additional 40 basis points in expected return to hold an adjacent stock portfolio with greater financial contagion beta. Sampling error in the two extreme portfolios causes the difference to be insignificant, similarly to the univariate case.

[ Insert Figure 6 about here ]

Figure 6 plots the wealth processes of investing in portfolios sorted on betas obtained from eqn. (11). Stocks are sorted into value-weighted terciles to reduce the effect of sampling error in 
the extreme deciles mentioned above. Portfolios are formed by buying the tercile with greatest

factor beta and selling the tercile with lowest factor beta and rebalanced monthly. Five years of observations are lost in acquiring the first beta estimates. The active strategy of investing in the HCMLC beta sorted long-short portfolio outperforms each of the other long-short portfolios sorted on the other factor betas. $\$ 1.00$ invested in January 1973 in the HCMLC beta sorted long-short portfolio becomes $\$ 3.99$ in October, 2011 with a Sharpe ratio of 0.43 (not reported). $\$ 1.00$ invested in the MRKT, SMB, HML, MOM, and LIQ beta sorted long-short portfolios become $\$ 0.48, \$ 2.33$, $\$ 2.52, \$ 1.25$, and $\$ 0.61$, respectively. Sharpe ratios (not reported) of the MRKT, SMB, HML, MOM, and LIQ beta sorted long-short portfolios are $-0.13,0.24,0.26,0.11$, and -0.06 , respectively.

\section{Financial Contagion Risk and the SDF}

Financial contagion risk is proposed to enter a linear SDF, $m_{t}$, given by

$$
\begin{gathered}
0=\mathbf{E}\left(m_{t+1} r_{i, t+1}^{e}\right) \\
m_{t}=1-b_{1} r_{M R K T, t}-b_{2} r_{S M B, t}-b_{3} r_{H M L, t}-b_{4} r_{M O M, t}-b_{5} r_{L I Q, t}-b_{6} r_{H C M L C, t} \\
\mathbf{E}\left(r_{i}^{e}\right)=b_{1} \operatorname{cov}\left(r_{i}^{e}, r_{M R K T}\right)+b_{2} \operatorname{cov}\left(r_{i}^{e}, r_{S M B}\right)+b_{3} \operatorname{cov}\left(r_{i}^{e}, r_{H M L}\right)+b_{4} \operatorname{cov}\left(r_{i}^{e}, r_{M O M}\right) \\
+b_{5} \operatorname{cov}\left(r_{i}^{e}, r_{L I Q}\right)+b_{6} \operatorname{cov}\left(r_{i}^{e}, r_{H C M L C}\right) \\
\mathbf{E}\left(r_{i}^{e}\right)=\lambda_{M R K T} \beta_{i, M R K T}+\lambda_{S M B} \beta_{i, S M B}+\lambda_{H M L} \beta_{i, H M L}+\lambda_{M O M} \beta_{i, M O M} \\
+\lambda_{L I Q} \beta_{i, L I Q}+\lambda_{H C M L C} \beta_{i, H C M L C}
\end{gathered}
$$

$r_{i}^{e}$ denotes stock or portfolio $i$ 's excess return, $\beta_{i, j}=\mathbf{C V}\left(r_{i}^{e}, r_{j, t}\right) / \mathbf{V}\left(r_{j, t}\right)$, and $\lambda_{j}$ is the price of risk associated with the $j$ 'th factor. Eqn. (12) is the no-arbitrage condition stating that riskadjusted stock returns have a price of zero and eqn. (13) specifies the linear form of the SDF. The beta pricing models in eqns. (14) and (15) are immediately implied. Eqn. (15) is estimated with the Fama-MacBeth (1973) two-stage regressions at the firm level without sorting the stocks into portfolios. 60-month rolling regressions are used in the first stage and the intercept term is excluded in the second stage regression. An intercept term is excluded in the second stage to avoid the restriction of a common underpricing or overpricing in the cross-section of returns that 
would result. Fama-MacBeth regressions are run with the HCMLC portfolio as the only factor, augmenting the CAPM with HCMLC, augmenting the FF3F model with HCMLC, and augmenting the FFCPS model with HCMLC.

\section{[ Insert Table VI about here ]}

Table VI presents risk premium results from the firm-level Fama-MacBeth regressions. The coefficient representing the HCMLC risk premium is stable across factor specifications. When HCMLC augments the CAPM, a risk premium of 5.4 percent is obtained. This premium is in line with the 6.0 percent sample mean return observed on the HCMLC portfolio. When the FF3F model is augmented with the HCMLC factor, a financial contagion risk premium of 4.0 percent is obtained. The estimated risk premium is 3.9 percent when the FFCPS model is augmented and it is 9.6 percent when HCMLC is the only factor. In all factor specifications, financial contagion risk premiums are statistically significant at the one percent level and of roughly the same magnitude as the market risk premium.

\section{[ Insert Table VII about here ]}

Table VII presents results of Fama-MacBeth regressions for a number of test portfolios. The test portfolios include the 49 industry portfolios, the 10 size sorted portfolios, the $10 \mathrm{~B} / \mathrm{M}$ sorted portfolios, the 10 momentum sorted portfolios, and the combination of the 25 size-B/M sorted portfolios and 10 momentum portfolios. Industry and momentum portfolios are included, in addition to the traditional size and B/M sorted ones, to satisfy "prescription 1" of Lewellen, Nagel, and Shanken (2010) for improving asset pricing tests since they do not correlate as highly with the SMB and HML returns. Results for both equally-weighted test portfolios and value-weighted test portfolios are presented. Financial contagion risk is significantly priced in all of the cross-sections of test portfolios. While the commonly used FFCPS factors are generally not priced in the 10 size and $10 \mathrm{~B} / \mathrm{M}$ portfolios when the HCMLC factor is included, they are generally significant when the HCMLC factor is not included. Also of note is the large financial contagion risk premium that the momentum portfolios price in. The annualized financial contagion risk premium for the ten momentum portfolios is 23.4 percent when the momentum portfolios are formed from equallyweighted stocks. Generally, however, the financial contagion risk premiums implied by the test 
portfolios are in the range of 5-15 percent. Statistically significant financial contagion risk premiums for the industry portfolios, size portfolios, B/M portfolios, and 25 size-B/M plus 10 momentum portfolios are 4.7 percent, 15.6 percent, 14.9 percent, and 5.8 percent, respectively.

\section{[ Insert Table VIII about here ]}

Table VIII formally tests if the out of sample Fama-MacBeth pricing errors are jointly equal to zero for each of the factor model specifications. The Chi-square test is used to test if all pricing errors are significantly different from zero

$$
\widehat{\boldsymbol{\alpha}}=T^{-1} \sum_{t=1}^{T} \widehat{\boldsymbol{\alpha}}_{t}, \quad \operatorname{cov}(\widehat{\boldsymbol{\alpha}})=T^{-2} \sum_{t=1}^{T}\left(\widehat{\boldsymbol{\alpha}}_{t}-\widehat{\boldsymbol{\alpha}}\right)\left(\widehat{\boldsymbol{\alpha}}_{t}-\widehat{\boldsymbol{\alpha}}\right)^{\prime}, \quad \widehat{\boldsymbol{\alpha}}^{\prime} \operatorname{cov}(\widehat{\boldsymbol{\alpha}}) \widehat{\boldsymbol{\alpha}} \sim \chi_{N-k}^{2}
$$

where $\widehat{\boldsymbol{\alpha}}_{t}$ is the vector of residuals in eqn. (15) estimated from the second-stage Fama-MacBeth regressions at each date, $N$ is the number of portfolios, and $k$ is the number of factors in the model. Pricing error results from the CAPM, FF3F, and FFCPS models are presented in columns two to four. Pricing error results when the HCMLC factor is the only factor are presented in the final column. The null hypothesis that pricing errors are jointly all equal to zero is generally rejected for all factor models and test portfolios. The HCMLC factor alone, however, prices assets at least as well as the other models in all cases and better than the CAPM and FF3F models for the 49 industry portfolios, the $10 \mathrm{~B} / \mathrm{M}$ portfolios, and the 25 size-B/M plus 10 momentum portfolios. That the HCMLC factor alone prices assets so successfully out of sample shows that financial contagion risk is an important source of the risk premium.

In addition to the out of sample Fama-MacBeth cross-sectional regressions, the price of contagion risk is also estimated in ex-post full sample two-pass cross-sectional regressions. Risk premium parameters in eqn. (15) are estimated using regular ordinary least squares (OLS) and two alternative specifications of feasible generalized least squares (FGLS). GLS estimators are included to accommodate the empirical regularity that the residuals from estimating models of the eqn. (15) are correlated. The two FGLS specifications differ in the assumed structure of the error variance matrix, $\Omega_{j}$ for $j \in\{1,2\}$. In the first specification, denoted $G L S_{1}$, errors are allowed to be heteroskedastic. 
Possible heteroskedasticity in the error variance is modeled as

$$
\begin{aligned}
\overline{\boldsymbol{r}}^{e} & =\widehat{\mathbf{B}} \boldsymbol{\Lambda}+\boldsymbol{v} \\
\widehat{\boldsymbol{v}}^{2} & =\left(\overline{\boldsymbol{r}}^{e}-\widehat{\mathbf{B}} \widehat{\boldsymbol{\Lambda}}_{O L S}\right) \circ\left(\overline{\boldsymbol{r}}^{e}-\widehat{\mathbf{B}} \widehat{\boldsymbol{\Lambda}}_{O L S}\right) \\
\ln \left(\widehat{\boldsymbol{v}}^{2}\right) & =c_{0}+\widehat{\mathbf{B}} \mathbf{C}+\boldsymbol{u} \\
\widehat{\widehat{\boldsymbol{v}}}^{2} & =\exp \left(\widehat{c}_{0}+\widehat{\mathbf{B}} \widehat{\mathbf{C}}\right) \\
\widehat{\boldsymbol{\Omega}}_{1} & =\operatorname{diag}\left(\widehat{\widehat{\boldsymbol{v}}}^{2}\right)
\end{aligned}
$$

Hats above variables denote that they have been estimated and o denotes the Hadamard elementby-element multiplication operator. Eqn. (17a) is the standard cross-sectional OLS equation corresponding to eqn. (15). $\overline{\boldsymbol{r}}^{e}$ denotes mean portfolio excess return. $c_{0}$ and $\mathbf{C}$ are a coefficient and a vector of coefficients to be estimated with eqn. (17c). $\widehat{\mathbf{B}}$ is the matrix of estimated betas where row $i$ of $\widehat{\mathbf{B}}$ is the transposed vector of beta coefficients estimated for portfolio $i$ from eqn. (11). $\Lambda$ is the vector of factor risk premium coefficients to be estimated in eqn. (15). Since $\Omega_{1}$ is a diagonal matrix, GLS $S_{1}$ is also the weighted least squares (WLS) estimator of risk-premiums. The second specification for the FGLS error variance matrix allows for correlated residuals across portfolios in eqn. (11)

$$
\begin{aligned}
\widehat{\boldsymbol{\varepsilon}}_{i} & =\boldsymbol{r}_{i}^{e}-\mathbf{F} \widehat{\boldsymbol{\beta}}_{i} \\
\widehat{\boldsymbol{\Omega}}_{2}^{(i, j)} & =\frac{\widehat{\boldsymbol{\varepsilon}}_{i}^{\prime} \widehat{\boldsymbol{\varepsilon}}_{j}}{(T-k)}
\end{aligned}
$$

Eqn. (18a) is eqn. (11) in matrix form and $\widehat{\Omega}_{2}^{(i, j)}$ denotes the $(i, j)$ element of the $\widehat{\Omega}_{2}$ matrix.

$$
\text { [ Insert Table IX about here ] }
$$

Table IX presents the cross-sectional risk premium results. Standard errors for the OLS regression are White (1980) heteroskedasticity consistent standard errors adjusted by the Shanken (1992) correction to account for portfolio betas being estimated in the first step. FGLS standard errors are also adjusted by the Shanken (1992) correction. Shanken correction factors are presented in the final column of the table. In the cross section, financial contagion risk is priced in all sets of test 
portfolios. Conservative estimates of the financial contagion risk premium estimated from the 49 industry portfolios, 10 size portfolios, 10 B/M portfolios, 10 momentum portfolios, and 25 size-B/M plus 10 momentum portfolios are 5.6 percent, 12.8 percent, 10.1 percent, 46.0 percent, and 10.2 percent, respectively. These risk premium results are generally close to the observed sample mean HCMLC portfolio return. Momentum portfolios, however, continue to price a large HCMLC risk premium. Adjusted $R^{2}$ statistics from estimating eqn. (15) with all factors are presented in the second to last column and adjusted $R^{2}$ statistics from estimating eqn. (15) without the HCMLC factor are presented in the third to last column. Model fit, measured by adjusted $R^{2}$, is improved by including the HCMLC factor in the 10 size portfolios, 10 momentum portfolios, and the 25 size-B/M plus 10 momentum portfolios. The largest increase in fit occurs for the 10 size portfolios where $G L S_{1}$ adjusted $R^{2}$ increases from 0.665 to 0.889 . OLS adjusted $R^{2}$ increases from 0.794 to 0.898. Note that since OLS, $G L S_{1}$, and $G L S_{2}$ each have different assumed error variance matrix, adjusted $R^{2}$ levels are not directly comparable across estimators. The change in adjusted $R^{2}$ for a given estimator is the statistic of interest.

\section{[ Insert Table X about here ]}

Table $\mathrm{X}$ presents chi-square statistics testing if the ex-post pricing errors from the cross sectional regressions are jointly equal to zero. The test statistic with the Shanken (1992) correction is

$$
\begin{aligned}
\operatorname{cov}(\widehat{\boldsymbol{\alpha}}) & =\frac{1}{T}\left(\boldsymbol{I}_{N}-\widehat{\boldsymbol{\beta}}\left(\widehat{\boldsymbol{\beta}}^{\prime} \widehat{\boldsymbol{\beta}}\right)^{-1} \widehat{\boldsymbol{\beta}}\right) \Sigma\left(\boldsymbol{I}_{N}-\widehat{\boldsymbol{\beta}}\left(\widehat{\boldsymbol{\beta}}^{\prime} \widehat{\boldsymbol{\beta}}\right)^{-1} \widehat{\boldsymbol{\beta}}\right)^{\prime} \times\left(1+\widehat{\boldsymbol{\lambda}}^{\prime} \Sigma_{f} \widehat{\boldsymbol{\lambda}}\right) \\
\widehat{\boldsymbol{\alpha}}^{\prime} \operatorname{cov}(\widehat{\boldsymbol{\alpha}}) \widehat{\boldsymbol{\alpha}} & \sim \chi_{N-k}^{2}
\end{aligned}
$$

where $\widehat{\boldsymbol{\alpha}}$ is the vector of estimated residuals from eqn. (15), $\widehat{\boldsymbol{\beta}}$ is the matrix of estimated factor loadings obtained from estimating eqn. (11) for the test portfolios and used in estimating eqn. (15), $\boldsymbol{\Sigma}$ is the variance-covariance matrix of estimated residuals from eqn. (11), $\boldsymbol{\Sigma}_{f}$ is the variancecovariance matrix of factor returns, and $\widehat{\boldsymbol{\lambda}}$ is the vector of estimated prices of risk from estimating eqn. (15) with OLS. Ex-post, HCMLC prices the test portfolios approximately as well as MRKT does. Ex-post, however, the FF3F model and the FFCPS models perform substantially better than the HCMLC model. This is to be as expected given the full sample of data and the additional 
dimensions with which the additional factors can match the data. Out of sample pricing errors, however, where the HCMLC model performs at least as well as the multifactor models is arguably the more important test of pricing ability.

\section{Robustness}

This section tests for beta estimation window robustness and subsample consistency of the price of financial contagion risk. Table XI presents second-stage risk-premium results from Fama-MacBeth regressions using the firm level common stock sample and using first-stage beta estimation windows ranging from 48 months to 120 months. With all estimation windows, the HCMLC portfolio obtains a significant risk premium at the one percent significance level. HCMLC risk premiums range from a low of 3.7 percent when the beta estimation window is 48 months to a high of 4.8 percent when the beta estimation window is 120 months.

\section{[ Insert Table XI and Table XII about here ]}

Table XII presents risk premium results for value-weighted test portfolios when the beta estimation window is varied in first-stage Fama-MacBeth regressions. Only risk-premium results for the HCMLC portfolio are presented to conserve space. Financial contagion risk premium results are robust across beta estimation windows for the 49 industry, $10 \mathrm{~B} / \mathrm{M}$, and 10 momentum portfolios. HCMLC risk-premiums are significantly different from zero for the 10 size portfolios when a 60-month beta estimation window is used and risk-premiums are only significant with 48-month or 84-month beta estimation windows for the 25 size-B/M plus 10 momentum portfolios. Of those significant HCMLC risk premiums estimated, the risk premium generally falls within 5.5 percent and 15.0 percent, in line with results presented earlier.

\section{[ Insert Table XIII about here ]}

Subsample consistency of the financial contagion risk premium is tested in Table XIII using the firm level common stock sample. Risk premium results from firm level second-stage Fama-MacBeth regressions during non-overlapping five year periods between 1975 and 2010 are presented. The five-year period prior to a five-year window beginning is used to compute the initial betas for 
the Fama-MacBeth regressions. For example, the cross-sectional test in January 1975 uses betas estimated from January 1970 to December 1974, the cross-sectional regression in February 1975 uses betas estimated from February 1970 to January 1975, and so on until the last cross-sectional regression in the 1975-1979 window would use betas estimated from January 1975 to November 1979. Estimated financial contagion risk premiums are robust to subsample window with risk premiums being significantly priced in the cross-section of stocks during the 1975-'79, 1985-'89, 1990-'94, and 1995-'99 periods. Estimated HCMLC risk premiums in these periods are 3.4 percent, 6.4 percent, 5.5 percent, and 8.3 percent, respectively. Regression slope and Kendall's tau estimates are presented in the final two columns. The null hypothesis of no monotonic relationship between decile HCMLC beta and decile mean return is rejected in the 1980-'84, 1995-'99, and 2000-'05 periods. During these periods, the average additional expected return that investors require to hold an adjacent stock decile with greater HCMLC beta is 83 basis points. Although not statistically significant in every subsample, in each 5-year subsample, investors require additional expected return to hold an adjacent portfolio with higher HCMLC beta except for the 2005-'10 period. In the 2005-'10 period, there is an insignificant negative relationship between HCMLC beta and portfolio return due to the financial crisis.

\section{[Insert Figure 7 about here]}

Figure 7 plots the smoothed time series of financial contagion premiums estimated from firmlevel Fama-MacBeth regressions. Shaded regions in the top panel are NBER recession dates and shaded regions in the bottom panel are U.S. banking crises dates from Reinhart and Rogoff (2011). The smoothed time series is obtained from running the following smoother twice

$$
\widehat{\widehat{\lambda}}_{H C M L C}=\sum_{m=-h}^{h}\left[\frac{h+1-|m|}{(h+1)^{2}}\right] \widehat{\lambda}_{H C M L C}
$$

where $h=23$ ( 5 percent of the sample size). In the top panel of Figure 7 , the HCMLC risk premium generally increases slightly during recessionary times. In the bottom panel, the HCMLC risk premium increases substantially during U.S. banking crises. The large peak in financial contagion that occurs outside of U.S. recessionary and banking crisis periods coincides with the Asian financial 
crisis. Figure 7 shows that investors demand a higher risk premium on stocks more susceptible to financial contagion risk during banking crises and to a lesser extent recessionary periods that are not primarily banking related.

\section{Conclusion}

Financial intermediaries serve as agents investing on households' behalf making them uniquely able to affect households' consumption opportunity sets. As the propensity for intermediaries to experience shocks simultaneously either endogenously or exogenously increases, households' payoffs experience greater covariation with their consumption possibilities. Modern portfolio theory proposes that assets that experience greater covariation in returns with aggregate consumption require a higher expected return. Therefore, investors will require a greater expected return on assets that covary more strongly with contagious intermediaries.

This paper contributes to the growing financial intermediary asset pricing literature by estimating intermediaries' contributions to aggregate financial contagion in a new state space framework and showing that financial contagion risk is priced in the cross section of stock returns. The financial contagion risk factor (HCMLC) is defined as the portfolio that buys the decile of financial intermediaries that contribute the most to financial contagion and sells the decile of intermediaries that contribute the least to financial contagion. Intermediaries in the high contagion decile outperform those in the low contagion decile by a risk-adjusted 3.9 percent. A monotonic relationship cannot be rejected between expected returns and financial contagion risk. Investors require an additional 80 basis points in expected return to hold an adjacent decile of financial institutions that experiences greater contagion risk and investors require an additional 40 basis points in expected return to hold an adjacent stock decile with greater financial contagion beta.

Intermediary contagion risk is priced in the out of sample cross-section of firm level common stock returns. Intermediary contagion risk is also priced in the ex-post cross-section of test portfolio returns that are sorted on size, B/M, momentum, and industry. The estimated risk premium of the HCMLC is generally within 5 percent to 15 percent, which is in line with the sample mean of 6 percent that the HCMLC portfolio obtains. Out of sample, the HCMLC factor prices portfolios at 
least as well as the CAPM, FF3F, and FFCPS models with superior pricing performance relative to the CAPM and FF3F models for the 49 industry portfolios, $10 \mathrm{~B} / \mathrm{M}$ portfolios, and the 25 sizeB/M plus 10 momentum portfolios. Risk premium results are robust to beta estimation window in Fama-MacBeth regressions and time period tested.

Ex-post, including the HCMLC factor in the FFCPS model also substantially improves model fit. Ex-post adjusted $R^{2}$ for modeling mean returns for the 10 size portfolios increases from 0.665 with the FFCPS to 0.889 once the HCMLC factor is included. Adjusted $R^{2}$ increases are also observed in the 10 momentum portfolios and the 25 size-B/M plus 10 momentum portfolios. The results in this paper indicate that financial contagion risk has important implications for asset prices and is an important source of the risk premium. 


\section{Appendix A The Kalman Filter Recursions}

The general state-space model (SSM) consists of the following observation and transition equations

$$
\begin{aligned}
& y_{i, t}=\mathbf{H}_{i, t} z_{i, t}+\mathbf{G}_{i, t} x_{i, t}+v_{i, t} \\
& z_{i, t}=\mathbf{B}_{i, t-1} z_{i, t-1}+\mathbf{F}_{i, t-1} x_{i, t-1}+\omega_{i, t}
\end{aligned}
$$

Eq. (A1) is the observation equation and eq. (A2) is the transition equation. $z_{i, t}$ is an $(N \times 1)$ state vector, $y_{i, t}$ is a $(K \times 1)$ vector observed time series, $\mathbf{H}_{i, t}$ is a $(K \times N)$ measurement matrix, $\mathbf{G}_{i, t}$ is a $(K \times M)$ input matrix for the observation equation, $\mathbf{B}_{i, t}$ is an $(N \times N)$ transition matrix, $v_{i, t}$ is a $(K \times 1)$ vector of noise, $\mathbf{F}_{i, t}$ is an $(N \times M)$ input matrix for the transition equation, $x_{i, t}$ is an $(M \times 1)$ vector of observable instruments, and $\omega_{i, t}$ is an $(N \times 1)$ vector of noise. Both $v_{i, t}$ and $\omega_{i, t}$ are assumed to be normally distributed random variables with $v_{i, t} \sim N\left(0, \sigma_{v_{i}}^{2}\right)$ and $\omega_{i, t} \sim N\left(0, \Sigma_{\omega_{i}}\right)$. $\Sigma_{\omega_{i}}$ is a diagonal matrix. Additionally, the initial state is normally distributed $z_{i, 0} \sim N\left(\bar{z}_{i, 0}, \Sigma_{0}\right)$. Although normality is assumed, it is still possible to justify the Kalman filter recursions if this is not the case ${ }^{3}$. In eqn. (1), $y_{i, t}=r_{i, t}, z_{i, t}=\left(\alpha_{i, t}, \boldsymbol{\beta}_{i, t}^{\prime}\right)^{\prime}, \mathbf{H}_{i, t}=\left(1, r_{m, t}\right)^{\prime}, \mathbf{B}_{i}=\mathbf{I}_{2}$, and $\mathbf{G}_{i}=\mathbf{F}_{i}=\mathbf{0}$. In eqn. (4), $y_{i, t}=\widehat{e}_{i, t}, z_{i, t}=z_{i, t}, \mathbf{H}_{i, t}=r_{I, t}^{(i)}, \mathbf{B}_{i}=1$, and $\mathbf{G}_{i}=\mathbf{F}_{i}=\mathbf{0}$.

The following additional notation is used in the Kalman Filter recursions, where $s<t$,

$$
\begin{aligned}
z_{t \mid s} & =\mathbf{E}\left(z_{t} \mid y_{1}, y_{2}, \ldots, y_{s}\right) \\
\Sigma_{z}(t \mid s) & =\mathbf{V}\left(z_{t} \mid y_{1}, y_{2}, \ldots, y_{s}\right) \\
y_{t \mid s} & =\mathbf{E}\left(y_{t} \mid y_{1}, y_{2}, \ldots, y_{s}\right) \\
\Sigma_{y}(t \mid s) & =\mathbf{V}\left(y_{t} \mid y_{1}, y_{2}, \ldots, y_{s}\right)
\end{aligned}
$$

Within the general SSM framework, eqns. (1) and (4) are estimated with the Kalman filter recursions with $\mathbf{B}, \mathbf{F}$, and $\mathbf{G}$ time invariant. The recursions consist of an initialization step, prediction

\footnotetext{
${ }^{3}$ See Lütkepohl (2005), ch. 18.
} 
step, and correction step, which are given below.

\section{Initialization :}

$$
\begin{aligned}
z_{i, 0 \mid 0} & =\bar{z}_{i, 0} \\
\Sigma_{i, z} & =(0 \mid 0)=\Sigma_{i, z}(0)
\end{aligned}
$$

Prediction Step $(1 \leq t \leq T)$ :

$$
\begin{aligned}
z_{i, t \mid t-1} & =\mathbf{B}_{i} z_{i, t-1 \mid t-1} \\
\Sigma_{i, z}(t \mid t-1) & =\mathbf{B}_{i} \Sigma_{i, z}(t-1 \mid t-1) \mathbf{B}_{i}^{\prime}+\Sigma_{\omega_{i}} \\
y_{i, t \mid t-1} & =\mathbf{H}_{i, t} z_{i, t \mid t-1} \\
\Sigma_{i, y}(t \mid t-1) & =\mathbf{H}_{i, t} \Sigma_{i, z}(t \mid t-1) \mathbf{H}_{i, t}^{\prime}+\sigma_{v_{i}}^{2}
\end{aligned}
$$

Correction Step $(1 \leq t \leq T)$ :

$$
\begin{aligned}
\mathbf{P}_{i, t} & =\Sigma_{i, z}(t \mid t-1) \mathbf{H}_{i, t}^{\prime} \Sigma_{i, y}(t \mid t-1)^{-1} \\
z_{i, t \mid t} & =z_{i, t \mid t-1}+\mathbf{P}_{i, t}\left(y_{i, t}-y_{i, t \mid t-1}\right) \\
\Sigma_{i, z}(t \mid t) & =\Sigma_{i, z}(t \mid t-1)-\mathbf{P}_{i, t} \Sigma_{i, y}(t \mid t-1) \mathbf{P}_{i, t}^{\prime}
\end{aligned}
$$




\section{Appendix B The Likelihood Function}

To begin the Kalman filter recursions, the initial parameter vector $\boldsymbol{\theta}_{i}=\left(\sigma_{v_{i}}^{2}, \boldsymbol{\iota}^{\prime} \sum_{\omega_{i}}, \bar{z}_{i, 0}, \operatorname{vech}\left(\sum_{i, z}(0)\right)^{\prime}\right)^{\prime}$ is required. $\iota$ is the unit vector and the vech matrix operator stacks only the elements ona nd below the main diagonal of a square matrix. $\boldsymbol{\theta}_{i}$ is estimated by maximizing the constrained log-likelihood function,

$$
\ln L\left(\boldsymbol{\theta}_{i} \mid y_{i}\right)=-\frac{T}{2} \ln (2 \pi)-\frac{1}{2} \sum_{t=1}^{T}\left|\Sigma_{i, y}(t \mid t-1)\right|-\frac{1}{2} \sum_{t=1}^{T}\left(y_{i, t}-y_{i, t \mid t-1}\right)^{2} / \Sigma_{i, y}(t \mid t-1)
$$

where $\left|\Sigma_{i, y}(t \mid t-1)\right|$ is the determinant of $\Sigma_{i, y}(t \mid t-1)$. The constraints are that $\sigma_{v_{i}}^{2}$, must be greater than equal to zero and that the main diagonal elements of $\Sigma_{\omega_{i}}$ and $\Sigma_{i, z}(0)$ must be greater than or equal to zero. Rather than adding constraints to the optimization problem, the constraints are implicitly imposed by maximizing (B1) over $\tilde{\boldsymbol{\theta}}_{i}=\left(\lambda_{1}, \boldsymbol{\lambda}_{2}, \bar{z}_{i, 0}, \text { vech }\left(\Sigma_{i, z}(0)\right)\right)^{\prime} . \lambda_{1}$ is a scalar, $\boldsymbol{\lambda}_{2}$ is a $(N \times 1)$ vector, $\bar{z}_{i, 0}$ is a $(N \times 1)$ vector, and $\operatorname{vech}\left(\sum_{i, z}(0)\right)$ is a $([N \cdot(N+1)] / 2 \times 1)$ vector. The optimum parameters in $\boldsymbol{\theta}_{i}$ are taken to be $\sigma_{v_{i}}^{2}=\sqrt{\left(\lambda_{1}\right)^{2}}, \Sigma_{\omega_{i}}=\sqrt{\operatorname{diag}\left(\boldsymbol{\lambda}_{2} \circ \boldsymbol{\lambda}_{2}\right)}, \bar{z}_{i, 0}$, and $\Sigma_{i, z}(0)$ with the absolute value of the main diagonal of $\Sigma_{i, z}(0)$ replacing its estimated main diagonal. $\operatorname{diag}(\cdot)$ is the operator that transforms a vector into a diagonal matrix with the $i$ 'th element of the vector as the $i i^{\prime}$ th element of the matrix and o denotes the Hadamard product.

Eq. (B1) is maximized using the Newton-Raphson method. Starting values for eqn. (1) are $\tilde{\boldsymbol{\theta}}_{i}^{\text {st }}=$ $\left(0.001, \boldsymbol{\iota}_{2}^{\prime}\left(0.001 \times \mathbf{I}_{2}\right), \widehat{\boldsymbol{\varphi}}_{i}, \operatorname{vech}\left(\widehat{\Sigma}_{\varphi_{i}}\right)^{\prime}\right)^{\prime} \cdot \widehat{\boldsymbol{\varphi}}_{i}$ is the vector of time-invariant parameter estimates from estimating eqn. (1) with OLS. $\widehat{\Sigma}_{\boldsymbol{\varphi}_{i}}$ is the variance-covariance matrix of the $\widehat{\boldsymbol{\varphi}}_{i}$ estimator. Starting values for eqn. (4) are $\tilde{\boldsymbol{\theta}}_{i}^{\text {st }}=\left(0.001,0.001, \widehat{\varphi}_{i}, \widehat{\sigma}_{\widehat{\varphi}}^{2}\right)^{\prime}$. $\widehat{\varphi}_{i}$ is the OLS estimate obtained from estimating eqn. (4). $\widehat{\sigma}_{\widehat{\varphi}}^{2}$ is the variance of the estimator $\widehat{\varphi}_{i}$. Convergence in the objective function is assumed to occur at iteration $m$ when the change in likelihood function value satisfies $\left\|\ln L\left(\boldsymbol{\theta}_{i} \mid y_{i}\right)^{(m)}-\ln L\left(\boldsymbol{\theta}_{i} \mid y_{i}\right)^{(m-1)}\right\| \leq 1 \times 10^{-9}$, where $\|\cdot\|$ denotes the Euclidean norm. All parameters to be optimized are robust to the choice of starting values. The optimum values of $\boldsymbol{\theta}_{i}$ are used to run through the Kalman filter recursions for the $i$ 'th bank. 


\section{References}

[1] Acharya, Viral, Douglas Gale, and Tanju Yorulmazer, 2011, Rollover risk and market freezes, Journal of Finance 66, 1177-1209.

[2] Adrian, Tobias, and Erkko Etula, and Tyler Muir, 2012, Financial intermediaries and the cross section of asset returns, Journal of Finance forthcoming.

[3] Adrian, Tobias, and Hyun Song Kim, 2014, Procyclical leverage and value-at-risk, Review of Financial Studies 27, 373-403.

[4] Allen, Franklin, and Douglas Gale, 2000, Financial contagion, Journal of Political Economy $108,1-33$.

[5] Allen, Linda, Turan Bali, and Yi Tang, 2012, Does systemic risk in the financial sector predict future economic downturns? Review of Financial Studies 25, 3000-3036.

[6] Bekaert, Geert, Campbell Harvey, and Angela Ng, 2005, Market integration and contagion, Journal of Business 78, 39-69.

[7] Benmelech, Efraim, and Nittai Bergman, 2011, Bankruptcy and the collateral channel, Journal of Finance 66, 337-378.

[8] Carhart, Mark, 1997, On persistence in mutual fund performance, Journal of Finance 52, $57-82$.

[9] Cochrane, John, 2011, Presidential address: discount rates, Journal of Finance 66, 1047-1108.

[10] Duchin, Ran, Oguzhan Ozbas, and Berk Sensoy, 2010, Costly external finance, corporate investment, and the subprime mortgage crisis, Journal of Financial Economics 97, 418-435.

[11] Fama, Eugene, and James MacBeth, 1973, Risk, return, and equilibrium: empirical tests, Journal of Political Economy 81, 607-636.

[12] He, Zhiguo, and Arvind Krishnamurthy, 2013, Intermediary asset pricing, American Economic Review 103, 732-770.

[13] Ivashina, Victoria, and David Scharfstein, 2010, Bank lending during the financial crisis if 2008, Journal of Financial Economics 97, 319-338.

[14] Jotikasthira, Chotibhak, Christian Lundblad, and Tarun Ramadorai, 2012, Asset fire sales and purchases and the international transmission of funding shocks, Journal of Finance 67, 2015-2050.

[15] Kendall, M. G., 1938, A new measure of rank correlation, Biometrika 30, 81-93.

[16] Kendall, M.G., 1975, Rank Correlation Methods, 4th edition (Griffin, London).

[17] Kiyotaki, Nobuhiro, and John Moore, 2002, Balance-sheet contagion, American Economic Review 92, 46-50. 
[18] Kodres, Laura, and Matthew Pritsker, 2002, A rational expectations model of financial contagion, Journal of Finance 57, 769-799.

[19] Kyle, Albert, and Wei Xiong, 2001, Contagion as a wealth effect, Journal of Finance 56, 1401-1440.

[20] Leitner, Yaron, 2005, Financial networks: contagion, commitment, and private sector bailouts, Journal of Finance 60, 2925-2953.

[21] Lewellen, Jonathan, Stefan Nagel, and Jay Shanken, 2010, A skeptical appraisal of asset pricing tests, Journal of Financial Economics 96, 175-194.

[22] Lütkepohl, Helmut, State space models, 2005, New Introduction to Multiple Time Series Analysis (Springer, New York).

[23] Newey, Whitney, and Kenneth West, 1987, A simple, positive-definite, heteroskedasticity and autocorrelation consistent covariance matrix, Econometrica 55, 703-708.

[24] Patton, Andrew, and Tarun Ramadorai, 2013, On the high-frequency dynamics of hedge fund risk exposures, Journal of Finance 68, 597-635.

[25] Pástor, Luboš, and Robert Stambaugh, 2003, Liquidity risk and expected stock returns, Journal of Political Economy 111, 642-685.

[26] Reinhart, Carmen, and Kenneth Rogoff, 2011, From financial crash to debt crisis, American Economic Review 101, 1676-1706.

[27] Schnabl, Philipp, 2012, The international transmission of bank liquidity shocks: evidence from an emerging market, Journal of Finance 67, 897-932.

[28] Shanken, Jay, 1992, On the estimation of beta pricing models, Review of Financial Studies 5, $1-34$.

[29] Shleifer, Andrei, and Robert Vishny, 1992, Liquidation values and debt capacity: a market equilibrium approach, Journal of Finance 47, 1343-1366.

[30] White, H., 1980, A heteroskedasticity-consistent covariance matrix estimator and a direct test for heteroskedasticity, Econometrica 48, 817-838. 
Table I

\section{Summary Statistics}

This table presents summary statistics for the daily sample of financial firms in panel A and the CRSP sample of stocks in panel B. PRICE is stock price, RET, is monthly stock total return, MVE is market value of equity (in billions), BIR is the bank index return, $\widehat{z}_{t \mid t}$ is the coefficient estimate in eqn. (4), $F C_{t}^{(i)}$ is the contribution of bank $i$ to financial contagion multiplied by 100 , and $F C_{t}$ is the financial contagion estimate obtained from eqn. (8). The bank sample in Panel A covers the period January 1, 1960 to December 31, 2012. Monthly stock and factor summary statistics are presented in panel B. VOL is monthly trading volume (in millions), MRKT is the excess market factor portfolio return, SMB is the small minus big factor portfolio return, HML is the high minus low factor portfolio return, MOM is the momentum factor portfolio return, LIQ is the tradable liquidity factor portfolio return, and HCMLC is the financial contagion factor portfolio return. The stock and factor sample in Panel B covers the period from January 1968 to December 2011.

\begin{tabular}{lcccccccc}
\hline \multicolumn{7}{c}{ Panel A: Bank Stock Summary Statistics } \\
\hline & $\mathrm{N}$ & MEAN & SD & MEDIAN & Q25 & Q75 & MIN & MAX \\
\hline PRICE & $5,783,608$ & 20.453 & 19.521 & 16.375 & 9.725 & 26.000 & 0.010 & 710.750 \\
RET & $5,783,608$ & 0.000 & 0.036 & 0.000 & -0.010 & 0.010 & -2.855 & 2.485 \\
MVE & $5,783,608$ & 1.426 & 8.910 & 0.077 & 0.026 & 0.302 & 0.000 & 286.494 \\
BIR & $5,783,608$ & 0.001 & 0.016 & 0.001 & -0.006 & 0.007 & -0.147 & 0.176 \\
$\widehat{z}_{t \mid t}$ & $5,783,608$ & 0.097 & 0.390 & 0.085 & 0.026 & 0.164 & -19.289 & 121.208 \\
$F C_{t}^{(i)}$ & $5,783,608$ & 0.032 & 0.139 & 0.001 & 0.000 & 0.008 & -1.400 & 3.884 \\
$F C_{t}$ & $5,783,608$ & 0.179 & 0.035 & 0.178 & 0.150 & 0.197 & 0.089 & 0.275 \\
\hline \multicolumn{7}{c}{ Panel B: Full } & Stock Sample and Factor Summary Statistics & \\
\hline PRICE & $2,501,921$ & 24.814 & 767.104 & 12.813 & 5.625 & 24.250 & 0.016 & $141,600.000$ \\
RET & $2,501,921$ & 0.012 & 0.177 & 0.000 & -0.067 & 0.072 & -0.981 & 24.000 \\
MVE & $2,501,921$ & 1.217 & 8.481 & 0.079 & 0.021 & 0.370 & 0.000 & 602.433 \\
VOL & $2,264,164$ & 6.670 & 62.983 & 0.403 & 0.081 & 2.280 & 0.000 & $20,124.269$ \\
MRKT & $2,501,921$ & 0.005 & 0.047 & 0.009 & -0.023 & 0.036 & -0.232 & 0.161 \\
SMB & $2,501,921$ & 0.001 & 0.033 & 0.000 & -0.017 & 0.021 & -0.164 & 0.220 \\
HML & $2,501,921$ & 0.004 & 0.031 & 0.004 & -0.013 & 0.019 & -0.126 & 0.138 \\
MOM & $2,501,921$ & 0.008 & 0.045 & 0.008 & -0.007 & 0.029 & -0.347 & 0.184 \\
LIQ & $2,501,921$ & 0.005 & 0.036 & 0.003 & -0.016 & 0.025 & -0.105 & 0.212 \\
HCMLC & $2,501,921$ & 0.006 & 0.039 & 0.005 & -0.020 & 0.032 & -0.120 & 0.166 \\
\hline
\end{tabular}


Table II

\section{Bank Contagion Portfolio Returns}

This table presents mean returns from contagion sorted bank portfolios in panel A. Each month, banks are sorted into equal-weighted portfolios based on their contribution to the total financial contagion estimate. In the following month returns on the portfolio are observed and banks are re-sorted. MEAN denotes the time series mean of portfolio returns, T-STAT tests if MEAN is statistically different from zero, and SHARPE presents the Sharpe ratio of the portfolio. D10 is the decile of most contagious banks, D1 is the decile of least contagious banks, Q5 is the quintile of most contagious banks, Q1 is the quintile of least contagious banks, T3 is the tercile of most contagious banks, and $\mathrm{T} 1$ is the tercile of least contagious banks. MVE is mean bank market value of equity (in billions) in the portfolio. In panel $\mathrm{B}$, portfolio returns are regressed on the FFCPS 5 factors

$$
r_{p, t}^{e}=\alpha_{p}+\beta_{p, M R K T} r_{M R K T, t}+\beta_{p, S M B} r_{S M B, t}+\beta_{p, H M L} r_{H M L, t}+\beta_{p, M O M} r_{M O M, t}+\beta_{p, L I Q} r_{L I Q, t}+\varepsilon_{p, t}
$$

ALPHA is the annualized regression intercept, MRKT denotes the excess market return, SMB is the return on the small-minus-big portfolio, HML is the return on the high book value minus low book value portfolio, MOM is the return on the winners minus losers portfolio, and LIQ is the return on high liquidity exposure minus low liquidity exposure portfolio. Stock returns are trimmed at the $2.5 \%$ and $97.5 \%$ levels. t-statistics are presented in parentheses. $* * *, * *$, and $*$ denote statistical significance at the $1 \%, 5 \%$, and $10 \%$ levels, respectively. The sample period covers from January 1968 to December 2011.

\begin{tabular}{|c|c|c|c|c|c|c|}
\hline \multicolumn{7}{|c|}{ Panel A: Portfolio Returns } \\
\hline & & & MEAN & T-STAT & SHARPE & MVE \\
\hline$\overline{\mathrm{D} 10}$ & & & $0.119^{* * *}$ & 4.472 & 0.372 & 8.303 \\
\hline D1 & & & $0.059^{* * *}$ & 3.592 & 0.049 & 0.273 \\
\hline Q5 & & & $0.122^{* * *}$ & 5.015 & 0.427 & 4.490 \\
\hline Q1 & & & $0.053^{* * *}$ & 3.516 & -0.002 & 0.155 \\
\hline T3 & & & $0.112^{* * *}$ & 4.903 & 0.386 & 2.788 \\
\hline T1 & & & $0.055^{* * *}$ & 3.717 & 0.019 & 0.106 \\
\hline D10-D1 & & & $0.060^{* * *}$ & 2.852 & 0.430 & . \\
\hline Q5-Q1 & & & $0.069^{* * *}$ & 3.900 & 0.588 & . \\
\hline $\mathrm{T} 3-\mathrm{T} 1$ & & & $0.057^{* * *}$ & 3.905 & 0.589 & . \\
\hline \multicolumn{7}{|c|}{ Panel B: Portfolio Abnormal Returns } \\
\hline & ALPHA & MRKT & SMB & HML & MOM & LIQ \\
\hline \multirow[t]{2}{*}{ D10 } & 0.010 & $0.932^{* * *}$ & $-0.094^{* *}$ & $0.375^{* * *}$ & $-0.051^{*}$ & -0.042 \\
\hline & $(0.588)$ & $(30.224)$ & $(-2.161)$ & (7.949) & $(-1.698)$ & $(-1.147)$ \\
\hline \multirow[t]{2}{*}{ D1 } & $-0.030 * *$ & $0.401^{* * *}$ & $0.315^{* * *}$ & $0.274^{* * *}$ & $-0.036^{*}$ & -0.028 \\
\hline & $(-2.469)$ & $(17.745)$ & (9.919) & (7.917) & $(-1.646)$ & $(-1.042)$ \\
\hline \multirow[t]{2}{*}{ Q5 } & 0.009 & $0.847^{* * *}$ & $0.075^{*}$ & $0.410^{* * *}$ & -0.020 & -0.033 \\
\hline & $(0.628)$ & $(30.687)$ & (1.944) & (9.709) & $(-0.747)$ & $(-0.996)$ \\
\hline \multirow[t]{2}{*}{ Q1 } & $-0.035^{* * *}$ & $0.382^{* * *}$ & $0.324^{* * *}$ & $0.269^{* * *}$ & -0.024 & -0.025 \\
\hline & $(-3.358)$ & $(19.252)$ & (11.624) & $(8.865)$ & $(-1.228)$ & $(-1.077)$ \\
\hline \multirow[t]{2}{*}{ T3 } & -0.002 & $0.776^{* * *}$ & $0.186^{* * *}$ & $0.417^{* * *}$ & -0.009 & -0.027 \\
\hline & $(-0.136)$ & $(30.858)$ & $(5.279)$ & $(10.856)$ & $(-0.350)$ & $(-0.910)$ \\
\hline \multirow[t]{2}{*}{$\mathrm{T} 1$} & $-0.034^{* * *}$ & $0.382^{* * *}$ & $0.311^{* * *}$ & $0.281^{* * *}$ & -0.019 & -0.028 \\
\hline & $(-3.298)$ & (19.739) & $(11.454)$ & $(9.521)$ & $(-1.028)$ & $(-1.204)$ \\
\hline \multirow[t]{2}{*}{ D10-D1 } & $0.039^{* *}$ & $0.531^{* * *}$ & $-0.409^{* * *}$ & $0.101^{*}$ & -0.015 & -0.014 \\
\hline & $(2.189)$ & (15.708) & $(-8.614)$ & (1.955) & $(-0.448)$ & $(-0.349)$ \\
\hline \multirow[t]{2}{*}{ Q5-Q1 } & $0.045^{* * *}$ & $0.466^{* * *}$ & $-0.248^{* * *}$ & $0.141^{* * *}$ & 0.004 & -0.007 \\
\hline & $(2.944)$ & (16.335) & $(-6.202)$ & (3.238) & (0.131) & $(-0.216)$ \\
\hline \multirow[t]{2}{*}{$\mathrm{T} 3-\mathrm{T} 1$} & $0.032^{* * *}$ & $0.394^{* * *}$ & $-0.125^{* * *}$ & $0.136^{* * *}$ & 0.011 & 0.000 \\
\hline & $(2.634)$ & $(17.212)$ & $(-3.871)$ & $(3.881)$ & $(0.483)$ & $(0.017)$ \\
\hline
\end{tabular}




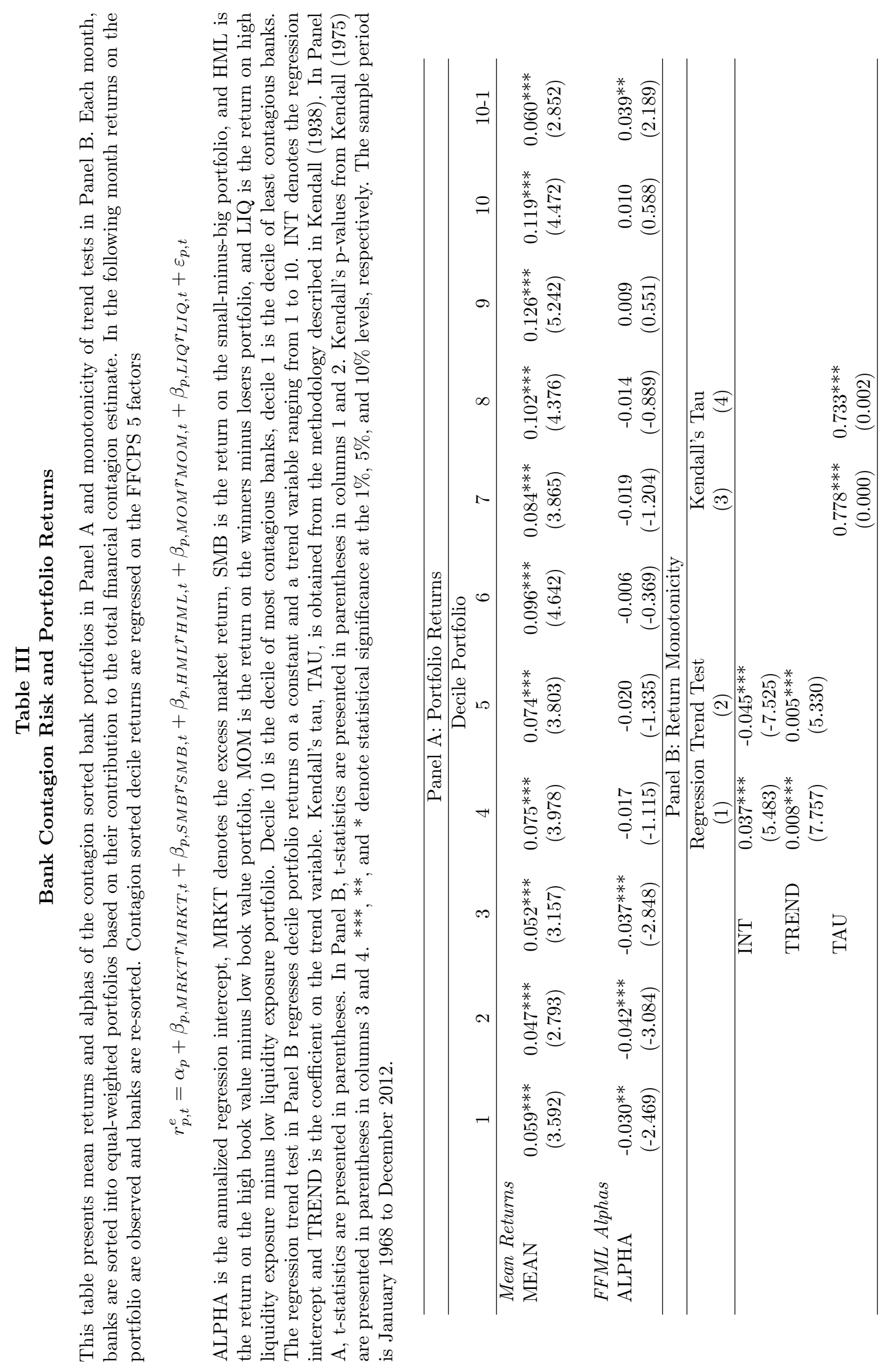


Table IV

\section{Factor Correlations}

This table presents the correlation matrix of monthly factor portfolio returns. HCMLC is the high contagionminus-low contagion bank portfolio return, MRKT denotes the excess market return, SMB is the return on the small-minus-big portfolio, and HML is the return on the high book value minus low book value portfolio, MOM is the return on the winners minus losers portfolio, LIQ is the return on high liquidity exposure minus low liquidity exposure portfolio, DEF is the monthly log change in the log difference between yields on Baa and Aaa rated bonds, and VIX is the monthly log return of the Chicago Board Options Exchange Volatility Index. Monthly data is used. The sample period covers January 1968 to December 2011 for correlations excluding the VIX. The sample period for correlations including the VIX is January 1990 to December 2011.

\begin{tabular}{lcccccccc}
\hline & MRKT & SMB & HML & MOM & LIQ & DEF & VIX & HCMLC \\
\hline MRKT & 1.000 & & & & & & & \\
SMB & 0.307 & 1.000 & & & & & & \\
HML & -0.321 & -0.241 & 1.000 & & & & & \\
MOM & -0.131 & -0.026 & -0.149 & 1.000 & & & & \\
LIQ & -0.052 & -0.039 & 0.031 & -0.023 & 1.000 & & & \\
DEF & 0.022 & -0.059 & -0.003 & -0.042 & -0.002 & 1.000 & & \\
VIX & -0.652 & -0.186 & 0.143 & 0.147 & -0.043 & 0.090 & 1.000 & \\
HCMLC & 0.494 & -0.152 & -0.042 & -0.099 & -0.029 & 0.111 & -0.344 & 1.000 \\
\hline
\end{tabular}




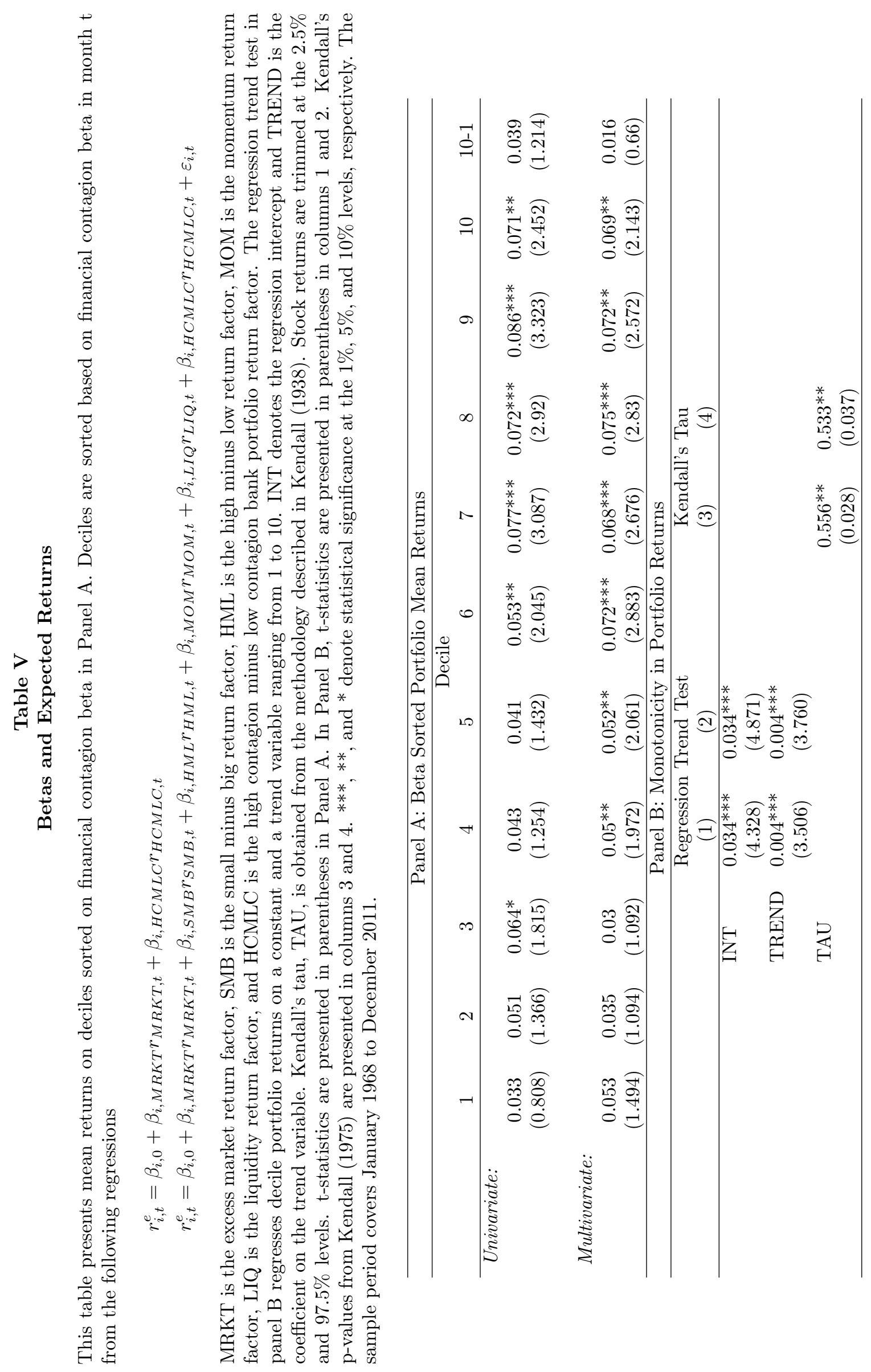


Table VI

Financial Contagion Risk Premium

This table presents the results of second-stage Fama and MacBeth (1973) regressions. A 60-month window is used for the first-stage beta estimations. Fama-MacBeth second-stage regressions are estimated without the intercept term

$$
\begin{aligned}
& r_{i, t}^{e}=\beta_{i, 0}+\beta_{i, M R K T} r_{M R K T, t}+\beta_{i, S M B} r_{S M B, t}+\beta_{i, M O M} r_{M O M, t} \\
& +\beta_{i, L I Q} r_{L I Q, t}+\beta_{i, H C M L C} r_{H C M L C, t}+\varepsilon_{i, t} \\
& r_{t+1}^{e}=\lambda_{M R K T} \widehat{\beta}_{M R K T, t}+\lambda_{S M B} \widehat{\beta}_{S M B, t}+\lambda_{H M L} \widehat{\beta}_{H M L, t} \\
& +\lambda_{M O M} \widehat{\beta}_{M O M, t}+\lambda_{L I Q} \widehat{\beta}_{L I Q, t}+\lambda_{H C M L C} \widehat{\beta}_{H C M L C, t}+u_{t} \\
& \bar{\lambda}_{k}=\frac{1}{T} \sum_{t=1}^{T} \widehat{\lambda}_{k, t} \\
& \sigma^{2}\left(\bar{\lambda}_{k}\right)=\widehat{h}(0)+2 \sum_{j=1}^{\lfloor 0.25 T\rfloor} w_{j} h(j) \\
& w_{j}=1-\frac{j}{\left(\left\lfloor T^{\frac{1}{4}}\right\rfloor+1\right)} \\
& \widehat{h}(j)=\frac{1}{T} \sum_{t=1}^{T-j}\left(\widehat{\lambda}_{k, t+j}-\bar{\lambda}_{k}\right)\left(\widehat{\lambda}_{k, t}-\bar{\lambda}_{k}\right)
\end{aligned}
$$

Annualized risk premium coefficients, $\bar{\lambda}_{k}$, are presented. t-statistics from Newey and West (1987) autocorrelation consistent standard errors, $\sqrt{\sigma^{2}\left(\bar{\lambda}_{k}\right)}$, are presented in parentheses. MRKT is the excess market return factor, SMB is the small minus big return factor, HML is the high minus low return factor, MOM is the momentum return factor, LIQ is the liquidity return factor, and HCMLC is the high contagion minus low contagion return factor. Returns are trimmed at the $2.5 \%$ and $97.5 \%$ levels. $* * *, * *$, and $*$ denote statistical significance at the $1 \%, 5 \%$, and $10 \%$ levels, respectively. The sample period covers 1968 to December 2011.

\begin{tabular}{lcccc}
\hline & HCMLC & CAPM & FF3F & FFCPS \\
\hline MRKT & & $0.057^{* *}$ & $0.047^{* *}$ & $0.047^{* *}$ \\
& & $(2.007)$ & $(1.941)$ & $(1.943)$ \\
SMB & & & 0.007 & 0.007 \\
& & & $(0.456)$ & $(0.446)$ \\
HML & & & $0.027^{* *}$ & $0.027^{* *}$ \\
& & & $(2.487)$ & $(2.517)$ \\
MOM & & & & 0.011 \\
& & & & $(1.036)$ \\
LIQ & & & & $-0.024^{* *}$ \\
& & & & $(-1.591)$ \\
HCMLC & $0.096^{* * *}$ & $0.054^{* * *}$ & $0.040^{* * *}$ & $0.039^{* * *}$ \\
& $(2.625)$ & $(3.971)$ & $(3.378)$ & $(3.348)$ \\
\hline
\end{tabular}


Table VII

Pricing Test Portfolios

This table presents the results of second-stage Fama and MacBeth (1973) regressions. The estimation procedure is the same as presented in table VI. MRKT is the excess market return factor, SMB is the small minus big return factor, HML is the high minus low return factor, MOM is the momentum return factor, LIQ is the liquidity factor, and HCMLC is the high contagion minus low contagion return factor. EQ WEIGHT indicates that the portfolio is equally-weighted and VA WEIGHT indicates that the portfolio is value-weighted. Portfolio returns are trimmed at the $2.5 \%$ and $97.5 \%$ levels in the first-stage factor regressions. t-statistics from Newey and West (1987) autocorrelation consistent standard errors are presented in parentheses. ${ }^{* * *},{ }^{* *}$, and $*$ denote statistical significance at the $1 \%, 5 \%$, and $10 \%$ levels, respectively. The sample period covers January 1968 to December 2011.

\begin{tabular}{|c|c|c|c|c|c|c|}
\hline & MRKT & SMB & HML & MOM & LIQ & HCMLC \\
\hline \multicolumn{7}{|l|}{49 Industry: } \\
\hline EQ WEIGHT & $\begin{array}{c}0.069^{* *} \\
(1.992)\end{array}$ & $\begin{array}{c}0.025 \\
(0.769)\end{array}$ & $\begin{array}{c}0.048^{* *} \\
(1.969)\end{array}$ & $\begin{array}{c}-0.012 \\
(-0.406)\end{array}$ & $\begin{array}{c}-0.066^{* *} \\
(-1.942)\end{array}$ & $\begin{array}{c}0.100^{* * *} \\
(2.655)\end{array}$ \\
\hline VA WEIGHT & $\begin{array}{c}0.090^{* * *} \\
(3.022)\end{array}$ & $\begin{array}{l}0.034^{*} \\
(1.500)\end{array}$ & $\begin{array}{c}0.027 \\
(1.490)\end{array}$ & $\begin{array}{l}-0.006 \\
(-0.240)\end{array}$ & $\begin{array}{l}-0.017 \\
(-0.596)\end{array}$ & $\begin{array}{l}0.047^{*} \\
(1.841)\end{array}$ \\
\hline \multicolumn{7}{|l|}{10 Size: } \\
\hline EQ WEIGHT & $\begin{array}{l}-0.036 \\
(-0.663)\end{array}$ & $\begin{array}{c}-0.004 \\
(-0.091)\end{array}$ & $\begin{array}{c}-0.036 \\
(-0.854)\end{array}$ & $\begin{array}{l}-0.064 \\
(-1.051)\end{array}$ & $\begin{array}{l}-0.066 \\
(-0.894)\end{array}$ & $\begin{array}{c}0.135^{* *} \\
(2.009)\end{array}$ \\
\hline VA WEIGHT & $\begin{array}{l}-0.030 \\
(-0.504)\end{array}$ & $\begin{array}{c}0.036 \\
(0.760)\end{array}$ & $\begin{array}{l}-0.048 \\
(-1.023)\end{array}$ & $\begin{array}{l}-0.003 \\
(-0.034)\end{array}$ & $\begin{array}{l}-0.117 \\
(-1.196)\end{array}$ & $\begin{array}{c}0.156^{* *} \\
(1.732)\end{array}$ \\
\hline \multicolumn{7}{|l|}{$10 \mathrm{~B} / \mathrm{M}$ : } \\
\hline EQ WEIGHT & $\begin{array}{c}0.111 \\
(1.286)\end{array}$ & $\begin{array}{l}0.102^{*} \\
(1.772)\end{array}$ & $\begin{array}{c}0.011 \\
(0.201)\end{array}$ & $\begin{array}{l}-0.105 \\
(-0.853)\end{array}$ & $\begin{array}{c}0.108 \\
(0.876)\end{array}$ & $\begin{array}{c}0.005 \\
(0.059)\end{array}$ \\
\hline VA WEIGHT & $\begin{array}{c}0.074 \\
(1.859)\end{array}$ & $\begin{array}{l}0.025 \\
(0.412)\end{array}$ & $\begin{array}{c}0.026 \\
(0.699)\end{array}$ & $\begin{array}{c}0.001 \\
(0.008)\end{array}$ & $\begin{array}{c}-0.043 \\
(-0.445)\end{array}$ & $\begin{array}{c}0.149^{* *} \\
(2.035)\end{array}$ \\
\hline \multicolumn{7}{|l|}{10 Momentum: } \\
\hline EQ WEIGHT & $\begin{array}{c}0.207^{* * *} \\
(2.779)\end{array}$ & $\begin{array}{l}0.124^{*} \\
(1.875)\end{array}$ & $\begin{array}{c}-0.007 \\
(-0.092)\end{array}$ & $\begin{array}{c}-0.241^{* *} \\
(-3.000)\end{array}$ & $\begin{array}{l}0.201^{*} \\
(2.298)\end{array}$ & $\begin{array}{c}0.234^{* *} \\
(2.201)\end{array}$ \\
\hline VA WEIGHT & $\begin{array}{c}0.089^{* *} \\
(1.762)\end{array}$ & $\begin{array}{c}0.061 \\
(1.821)\end{array}$ & $\begin{array}{c}0.010 \\
(0.199)\end{array}$ & $\begin{array}{l}-0.105 \\
(-1.721)\end{array}$ & $\begin{array}{c}0.054 \\
(1.035)\end{array}$ & $\begin{array}{c}0.076 \\
(1.271)\end{array}$ \\
\hline $\begin{array}{l}25 \text { Size- } B / M+10 \text { Momentum: } \\
\text { EQ WEIGHT }\end{array}$ & $\begin{array}{c}0.118^{* * *} \\
(2.920)\end{array}$ & $\begin{array}{c}0.076^{* * *} \\
(2.633)\end{array}$ & $\begin{array}{l}0.039^{*} \\
(1.678)\end{array}$ & $\begin{array}{l}-0.006 \\
(-0.121)\end{array}$ & $\begin{array}{c}0.049 \\
(1.440)\end{array}$ & $\begin{array}{l}0.058^{*} \\
(2.053)\end{array}$ \\
\hline VA WEIGHT & $\begin{array}{c}0.111^{* * *} \\
(2.949)\end{array}$ & $\begin{array}{c}0.057^{* * *} \\
(2.054)\end{array}$ & $\begin{array}{c}0.044^{* *} \\
(1.862)\end{array}$ & $\begin{array}{l}0.059^{*} \\
(1.734)\end{array}$ & $\begin{array}{l}0.052^{*} \\
(1.520)\end{array}$ & $\begin{array}{c}0.034 \\
(1.042)\end{array}$ \\
\hline
\end{tabular}


Table VIII

\section{Ex-ante Pricing Error Tests}

This table presents Chi-square tests testing if all pricing errors are jointly equal to zero. Fama-MacBeth (1973) regressions are used. A 60-month window is used for the first-stage beta estimations and second-stage regressions are estimated without the intercept term

$$
\begin{aligned}
r_{i, t}^{e}= & \beta_{i, 0}+\beta_{i, M R K T} r_{M R K T, t}+\beta_{i, S M B} r_{S M B, t}+\beta_{i, H M L} r_{H M L, t}+\beta_{i, M O M} r_{M O M, t} \\
& +\beta_{i, L I Q} r_{L I Q, t}+\beta_{i, H C M L C} r_{H C M L C, t}+\varepsilon_{i, t}
\end{aligned}
$$

$\chi_{N-k}^{2}$ estimates are presented. MRKT is the excess market return factor, SMB is the small minus big return factor, HML is the high minus low return factor, MOM is the momentum return factor, LIQ is the liquidity return factor, and HCMLC is the high contagion minus low contagion return factor. Returns are trimmed at the $2.5 \%$ and $97.5 \%$ levels. ${ }^{* * *},{ }^{* *}$, and ${ }^{*}$ denote statistical significance at the $1 \%, 5 \%, 10 \%$ levels, respectively. The sample period covers January 1968 to December 2011.

\begin{tabular}{lcccc}
\hline & CAPM & FF3F & FFCPS & HCMLC \\
\hline 49 Industry & $72.871^{* * *}$ & $76.421^{* * *}$ & $70.001^{* * *}$ & $70.803^{* *}$ \\
10 Size & 11.900 & 5.666 & $10.796^{*}$ & $15.724^{*}$ \\
$10 \mathrm{~B} / \mathrm{M}$ & $37.488^{* * *}$ & $31.617^{* * *}$ & $20.624^{* * *}$ & $26.655^{* * *}$ \\
10 Momentum & $35.751^{* * *}$ & $18.024^{* *}$ & $14.104^{* *}$ & $29.615^{* * *}$ \\
25 Size-B/M+10 Momentum & $130.849^{* * *}$ & $112.885^{* * *}$ & $108.616^{* * *}$ & $101.926^{* * *}$ \\
\hline
\end{tabular}




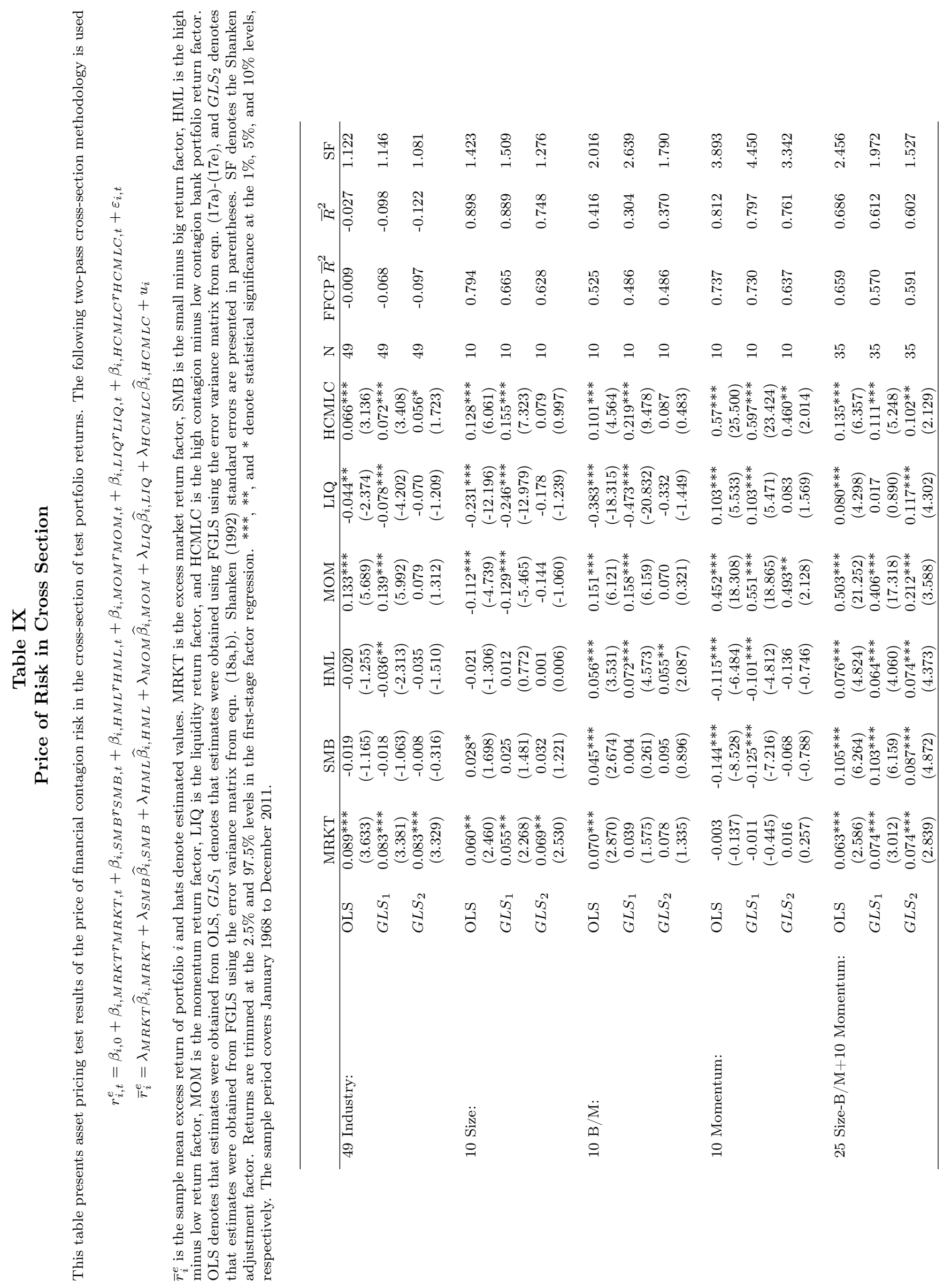


Table X

\section{Ex-post Pricing Error Tests}

This table presents Chi-square tests testing if all pricing errors are jointly equal to zero. Two-pass cross sectional regressions are used

$$
\begin{aligned}
r_{i, t}^{e}= & \beta_{i, 0}+\beta_{i, M R K T} r_{M R K T, t}+\beta_{i, S M B} r_{M R K T, t}+\beta_{i, H M L} r_{H M L, t}+\beta_{i, M O M} r_{M O M, t} \\
& +\beta_{i, L I Q} r_{L I Q, t}+\beta_{i, H C M L C} r_{H C M L C, t}+\varepsilon_{i, t}
\end{aligned}
$$

$\chi_{N-k}^{2}$ estimates are presented. MRKT is the excess market return factor, SMB is the small minus big return factor, HML is the high minus low return factor, MOM is the momentum return factor, LIQ is the liquidity return factor, and HCMLC is the high contagion minus low contagion return factor. Returns are trimmed at the $2.5 \%$ and $97.5 \%$ levels. ${ }^{* * *},{ }^{* *}$, and ${ }^{*}$ denote statistical significance at the $1 \%, 5 \%, 10 \%$ levels, respectively. The sample period covers January 1968 to December 2011.

\begin{tabular}{lcccc}
\hline & CAPM & FF3F & FFCPS & HCMLC \\
\hline 49 Industry & $64.225^{*}$ & $67.360^{* *}$ & $58.329^{*}$ & $70.201^{* *}$ \\
10 Size & 12.422 & 4.436 & 2.683 & 13.641 \\
$10 \mathrm{~B} / \mathrm{M}$ & $26.436^{* * *}$ & $13.387^{*}$ & 7.122 & $24.443^{* * *}$ \\
10 Momentum & $45.246^{* * *}$ & $14.311^{* *}$ & $9.448^{*}$ & $39.987^{* * *}$ \\
25 Size-B/M+10 Momentum & $111.898^{* * *}$ & $92.320^{* * *}$ & 60.723 & $114.150^{* * *}$ \\
\hline
\end{tabular}


Table XI

\section{Beta Estimation Robustness}

This table presents the results of second-stage Fama and MacBeth (1973) regressions for the firm-level stock sample. The estimation procedure is the same as in table VI, except monthly beta estimation windows in the first-stage regression are varied. MRKT is the excess market return factor, SMB is the small minus big return factor, HML is the high minus low return factor, MOM is the momentum return factor, LIQ is the liquidity return factor, and HCMLC is the high contagion minus low contagion return factor. Stock returns are trimmed at the $2.5 \%$ and 97.5\% levels. t-statistics from Newey and West (1987) autocorrelation consistent standard errors are presented in parentheses. $* * *, * *$, and $*$ denote statistical significance at the $1 \%, 5 \%$, and $10 \%$ levels, respectively. The sample period covers January 1968 to December 2011.

\begin{tabular}{ccccccc}
\hline & MRKT & SMB & HML & MOM & LIQ & HCMLC \\
\hline 48 mos & $0.041^{*}$ & 0.004 & $0.027^{* * *}$ & $0.015^{* *}$ & -0.018 & $0.035^{* * *}$ \\
& $(1.707)$ & $(0.286)$ & $(2.621)$ & $(1.368)$ & $(-1.134)$ & $(3.342)$ \\
$60 \mathrm{mos}$ & $0.047^{* *}$ & 0.007 & $0.027^{* *}$ & 0.011 & $-0.024^{* *}$ & $0.039^{* * *}$ \\
& $(1.943)$ & $(0.446)$ & $(2.517)$ & $(1.036)$ & $(-1.591)$ & $(3.348)$ \\
$72 \mathrm{mos}$ & $0.056^{* *}$ & 0.010 & $0.027^{* *}$ & 0.004 & $-0.024^{* *}$ & $0.041^{* * *}$ \\
& $(2.284)$ & $(0.648)$ & $(2.253)$ & $(0.287)$ & $(-1.619)$ & $(3.160)$ \\
$84 \mathrm{mos}$ & $0.066^{* * *}$ & 0.009 & $0.025^{* *}$ & 0.002 & $-0.026^{* *}$ & $0.048^{* * *}$ \\
& $(2.864)$ & $(0.597)$ & $(1.845)$ & $(0.139)$ & $(-1.662)$ & $(3.683)$ \\
$96 \mathrm{mos}$ & $0.062^{* * *}$ & 0.007 & $0.028^{* *}$ & 0.003 & $-0.024^{*}$ & $0.044^{* * *}$ \\
& $(2.720)$ & $(0.409)$ & $(2.191)$ & $(0.188)$ & $(-1.53)$ & $(3.197)$ \\
$108 \mathrm{mos}$ & $0.064^{* * *}$ & 0.005 & $0.022^{*}$ & 0.006 & $-0.022^{*}$ & $0.047^{* * *}$ \\
& $(2.700)$ & $(0.276)$ & $(1.666)$ & $(0.333)$ & $(-1.29)$ & $(3.171)$ \\
$120 \mathrm{mos}$ & $0.068^{* * *}$ & 0.005 & $0.022^{*}$ & 0.008 & -0.015 & $0.048^{* * *}$ \\
& $(2.722)$ & $(0.285)$ & $(1.538)$ & $(0.440)$ & $(-0.819)$ & $(3.027)$ \\
\hline
\end{tabular}




\section{Table XII}

\section{Beta Estimation Robustness: Test Portfolios}

This table presents the results of second-stage Fama and MacBeth (1973) regressions for test portfolios. The estimation procedure is the same as in table VI, except monthly beta estimation windows in the first-stage regression are varied. MRKT is the excess market return factor, SMB is the small minus big return factor, HML is the high minus low return factor, MOM is the momentum return factor, LIQ is the liquidity return factor, and HCMLC is the high contagion minus low contagion return factor. Test portfolios are value-weighted. Test portfolio returns are trimmed at the $2.5 \%$ and $97.5 \%$ levels. t-statistics from Newey and West (1987) autocorrelation consistent standard errors are presented in parentheses. ${ }^{* * *},{ }^{* *}$, and ${ }^{*}$ denote statistical significance at the $1 \%, 5 \%$, and $10 \%$ levels, respectively. The sample period covers January 1968 to December 2011.

\begin{tabular}{lccccccc}
\hline & $48 \mathrm{mos}$ & $60 \mathrm{mos}$ & $72 \mathrm{mos}$ & $84 \mathrm{mos}$ & $96 \mathrm{mos}$ & $108 \mathrm{mos}$ & $120 \mathrm{mos}$ \\
\hline 49 Industry & $0.075^{* * *}$ & $0.047^{*}$ & $0.042^{*}$ & $0.055^{* *}$ & $0.056^{* *}$ & $0.057^{* *}$ & $0.054^{*}$ \\
& $(2.891)$ & $(1.841)$ & $(1.634)$ & $(2.176)$ & $(1.890)$ & $(1.797)$ & $(1.647)$ \\
$10 \mathrm{Size}$ & 0.093 & $0.156^{* *}$ & 0.026 & -0.014 & 0.006 & -0.054 & -0.048 \\
& $(1.091)$ & $(1.732)$ & $(0.362)$ & $(-0.198)$ & $(0.092)$ & $(-0.838)$ & $(-0.645)$ \\
$10 \mathrm{~B} / \mathrm{M}$ & $0.135^{* *}$ & $0.149^{* *}$ & $0.192^{* * *}$ & $0.176^{* * *}$ & 0.084 & 0.067 & 0.125 \\
& $(2.011)$ & $(2.035)$ & $(2.677)$ & $(2.857)$ & $(1.290)$ & $(0.991)$ & $(1.751)$ \\
10 Momentum & 0.008 & 0.076 & $0.134^{*}$ & 0.133 & 0.055 & $0.166^{*}$ & $0.384^{* * *}$ \\
& $(0.092)$ & $(1.271)$ & $(1.958)$ & $(1.503)$ & $(0.603)$ & $(1.920)$ & $(4.322)$ \\
& $0.059^{* *}$ & 0.034 & 0.048 & $0.053^{*}$ & 0.028 & 0.041 & 0.047 \\
& $(2.051)$ & $(1.042)$ & $(1.488)$ & $(1.736)$ & $(0.731)$ & $(1.094)$ & $(1.242)$ \\
\hline
\end{tabular}


Table XIII

\section{Subsample Robustness}

This table presents the results of second-stage Fama and MacBeth (1973) regressions using the common stock sample. The estimation procedure is the same as presented in table VI. MRKT is the excess market return factor, SMB is the small minus big return factor, HML is the high minus low return factor, MOM is the momentum return factor, LIQ is the liquidity return factor, and HCMLC is the high contagion minus low contagion return factor. TREND and TAU are defined in tables III and V. Stock returns are trimmed at the $2.5 \%$ and $97.5 \%$ levels. t-statistics from Newey and West (1987) autocorrelation consistent standard errors are presented in parentheses. ${ }^{* * *},{ }^{* *}$, and ${ }^{*}$ denote statistical significance at the $1 \%, 5 \%$, and $10 \%$ levels, respectively.

\begin{tabular}{ccccccccc}
\hline & MRKT & SMB & HML & MOM & LIQ & HCMLC & TREND & TAU \\
\hline $1975-1980$ & $0.143^{* *}$ & $0.104^{* *}$ & -0.001 & -0.007 & $-0.066^{*}$ & $0.034^{* * *}$ & 0.007 & 0.378 \\
& $(2.600)$ & $(2.103)$ & $(-0.054)$ & $(-0.266)$ & $(-1.514)$ & $(4.025)$ & $(1.605)$ & $(0.156)$ \\
$1980-1985$ & 0.034 & $0.056^{*}$ & $0.044^{*}$ & 0.017 & -0.041 & 0.050 & $0.007^{* * *}$ & $0.556^{* *}$ \\
& $(0.456)$ & $(1.166)$ & $(2.403)$ & $(0.689)$ & $(-0.805)$ & $(1.186)$ & $(3.679)$ & $(0.028)$ \\
$1985-1990$ & 0.064 & 0.000 & 0.014 & -0.006 & $0.043^{* *}$ & $0.064^{*}$ & 0.004 & 0.244 \\
& $(1.004)$ & $(0.017)$ & $(0.699)$ & $(-0.600)$ & $(1.550)$ & $(1.677)$ & $(1.526)$ & $(0.380)$ \\
$1990-1995$ & 0.040 & 0.003 & -0.003 & -0.025 & -0.022 & $0.055^{*}$ & 0.000 & 0.067 \\
& $(0.515)$ & $(0.076)$ & $(-0.097)$ & $(-0.902)$ & $(-1.005)$ & $(1.695)$ & $(0.077)$ & $(0.862)$ \\
$1995-2000$ & $0.086^{*}$ & 0.001 & 0.000 & -0.019 & 0.014 & $0.083^{* * *}$ & $0.009^{* * *}$ & $0.733^{* * *}$ \\
& $(1.729)$ & $(0.043)$ & $(-0.008)$ & $(-0.661)$ & $(1.041)$ & $(2.776)$ & $(5.065)$ & $(0.002)$ \\
$2000-2005$ & 0.029 & -0.010 & $0.100^{*}$ & $0.046^{*}$ & $-0.129^{* * *}$ & 0.010 & $0.009^{*}$ & 0.422 \\
& $0.437)$ & $(-0.155)$ & $(2.669)$ & $(1.316)$ & $(-2.444)$ & $(0.329)$ & $(1.687)$ & $(0.108)$ \\
$2005-2010$ & 0.012 & -0.036 & 0.021 & $0.055^{* *}$ & -0.004 & 0.021 & -0.004 & -0.089 \\
& $0.131)$ & $(-1.007)$ & $(1.279)$ & $(1.959)$ & $(-0.118)$ & $(0.840)$ & $(-1.160)$ & $(0.762)$ \\
\hline
\end{tabular}




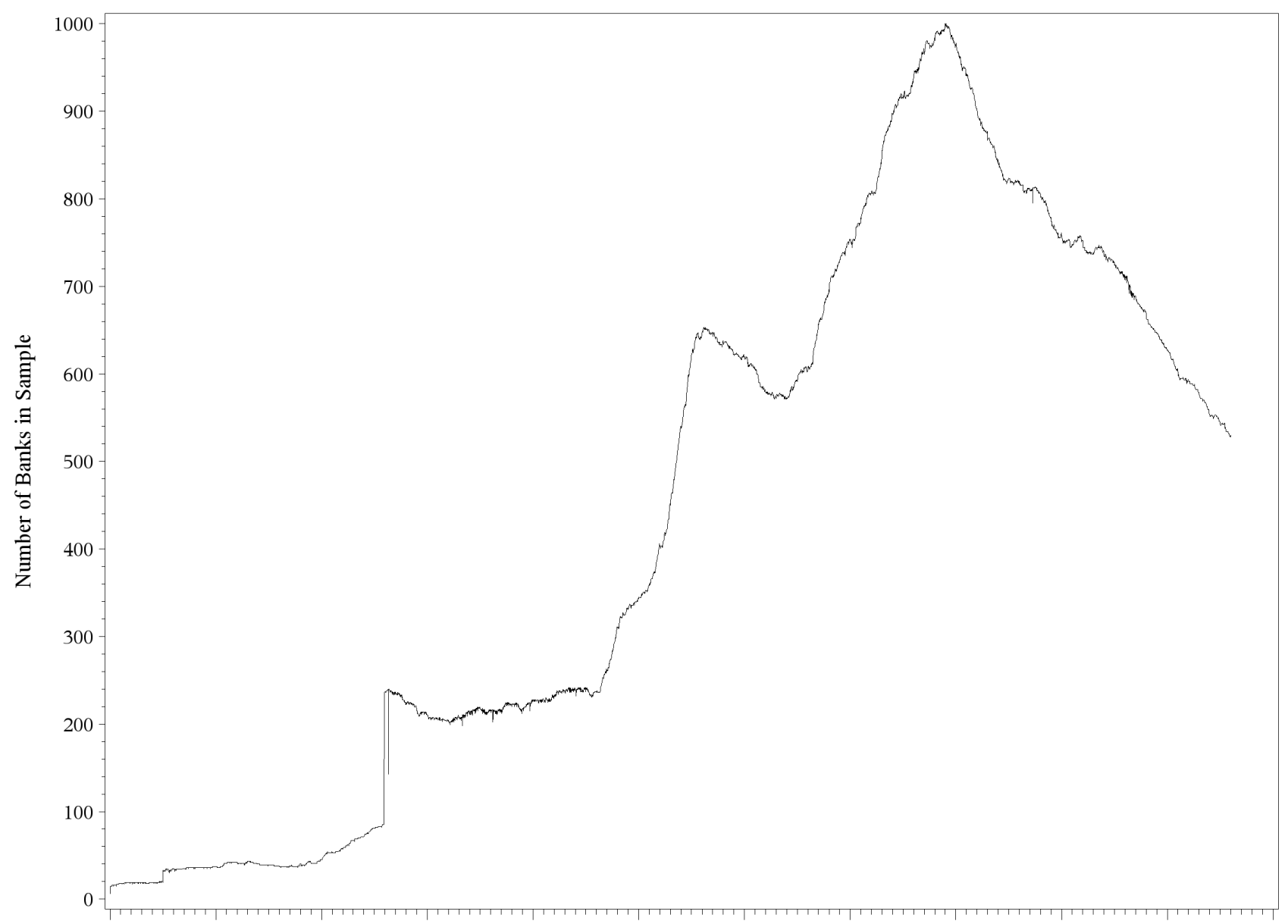

1960-01-01 1965-01-01 1970-01-01 $1975-01-01 \quad 1980-01-01 \quad 1985-01-01 \quad 1990-01-01 \quad 1995-01-01 \quad 2000-01-01 \quad 2005-01-01 \quad 2010-01-01 \quad 2015-01-01$ Date

Figure 1 Bank Sample Size Time Series. This figure plots the time series of banks (CRSP SIC codes 6000-6299 and share code 10 or 11) contemporaneously present in the sample. 


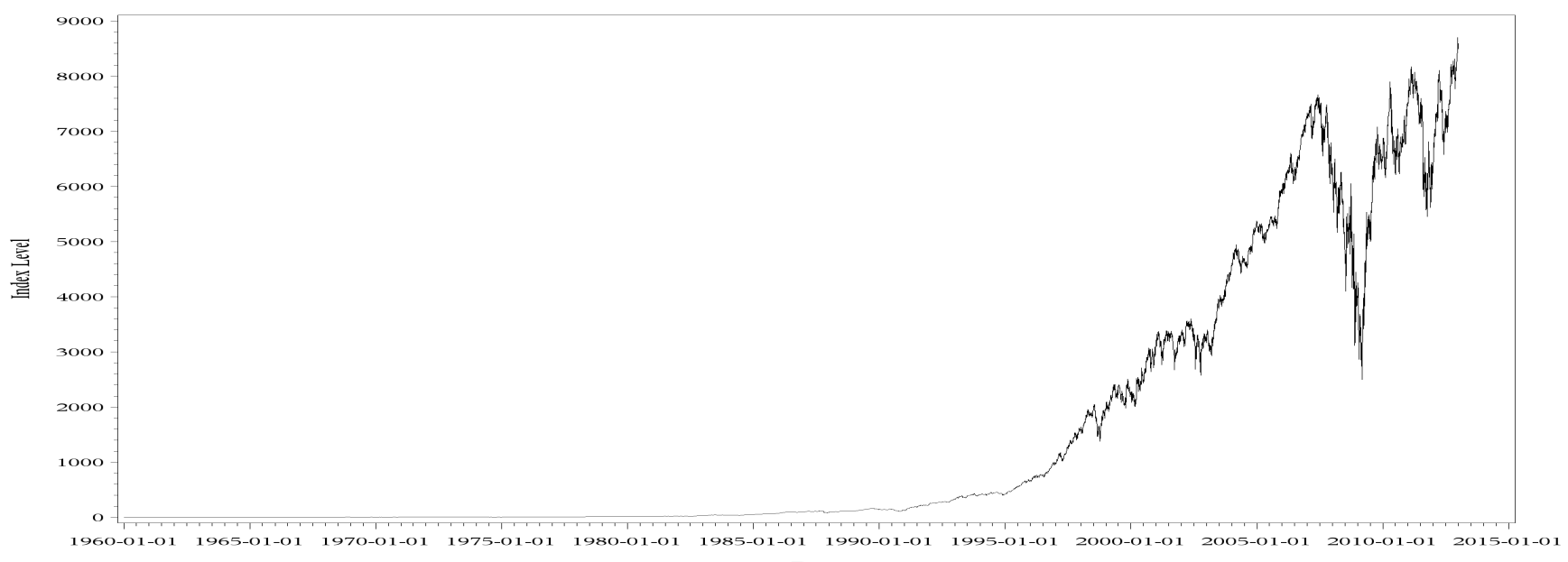
Date
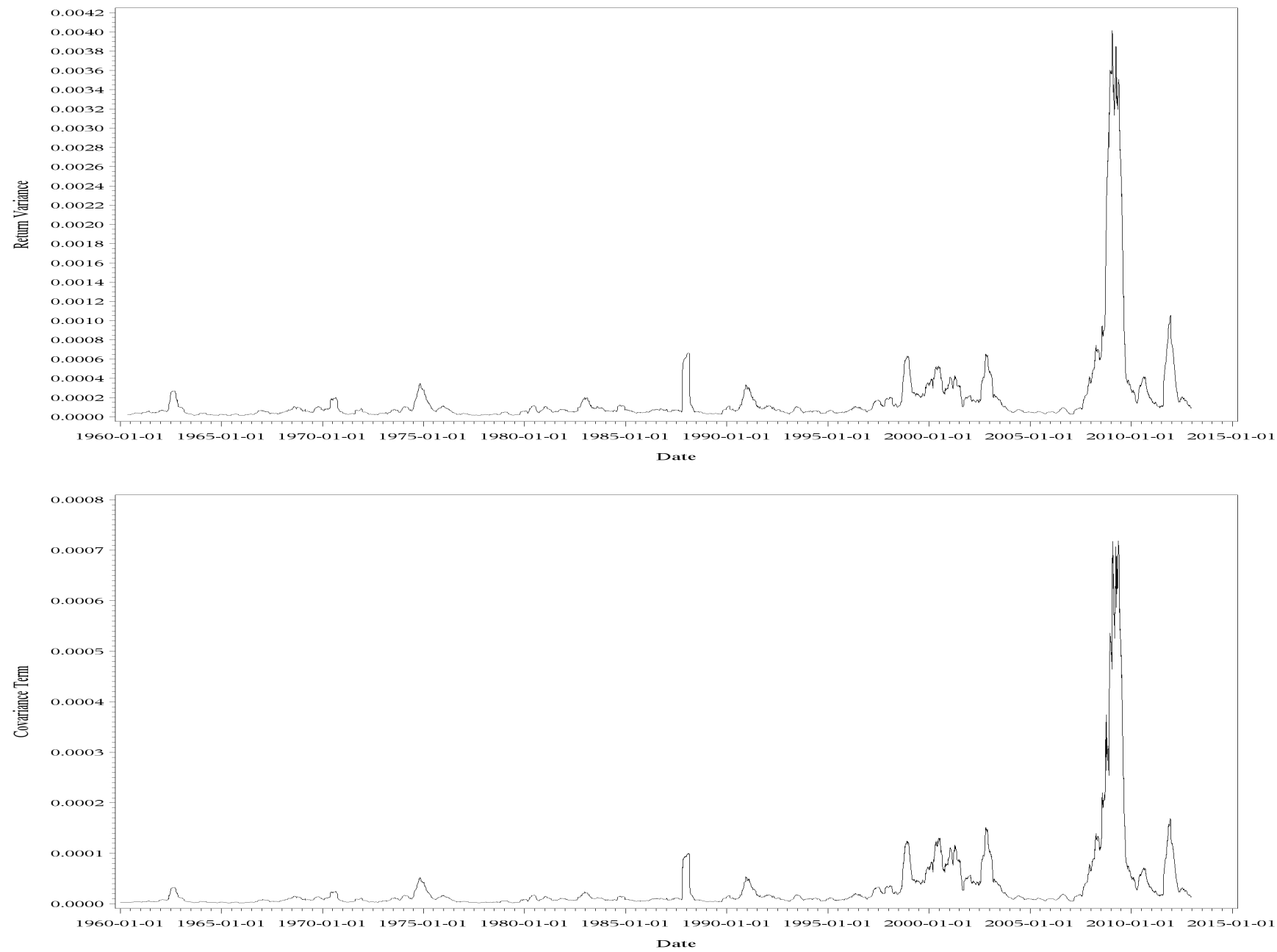

Figure 2 Bank Index Time Series. This figure plots the time series of the value-weighted bank index in the top panel, the time series of bank index return variance given by eqn. (7b) in the middle panel, and the time series of the covariance term of bank index return variance in the bottom panel. The bank index is constructed as the market-value weighted return of the bank sample. The base level for the bank index is set equal to one on January 1, 1960. Eqns. (7a,b) are used to obtain the return variance and covariances are obtained from $F C_{t} \widehat{\sigma}_{r_{I, t}}^{2} . F C_{t}$ and $\widehat{\sigma}_{r_{I, t}}^{2}$ are given by eqns. (8) and (7b), respectively. 


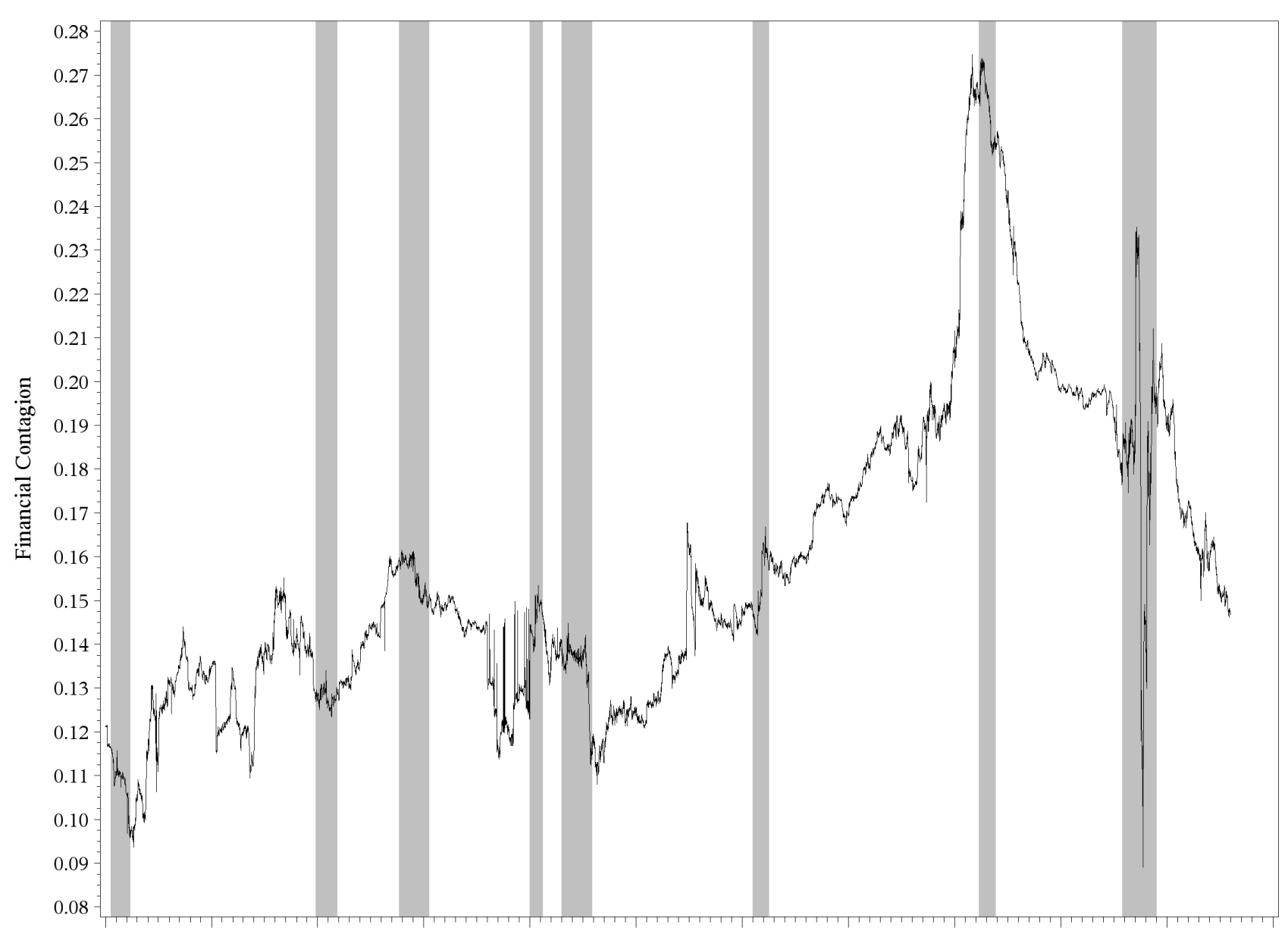

1960-01-01 1965-01-01 1970-01-01 1975-01-01 $\quad$ 1980-01-01 $\quad$ 1985-01-01 $1990-01-01 \quad 1995-01-01 \quad 2000-01-01 \quad 2005-01-01 \quad 2010-01-01 \quad 2015-01-01$

\section{Date}

Figure 3 Financial Contagion Time Series. This figure plots the time series of financial contagion, $F C_{t}$, obtained from eqn. (8). Shaded regions are NBER recession dates. 


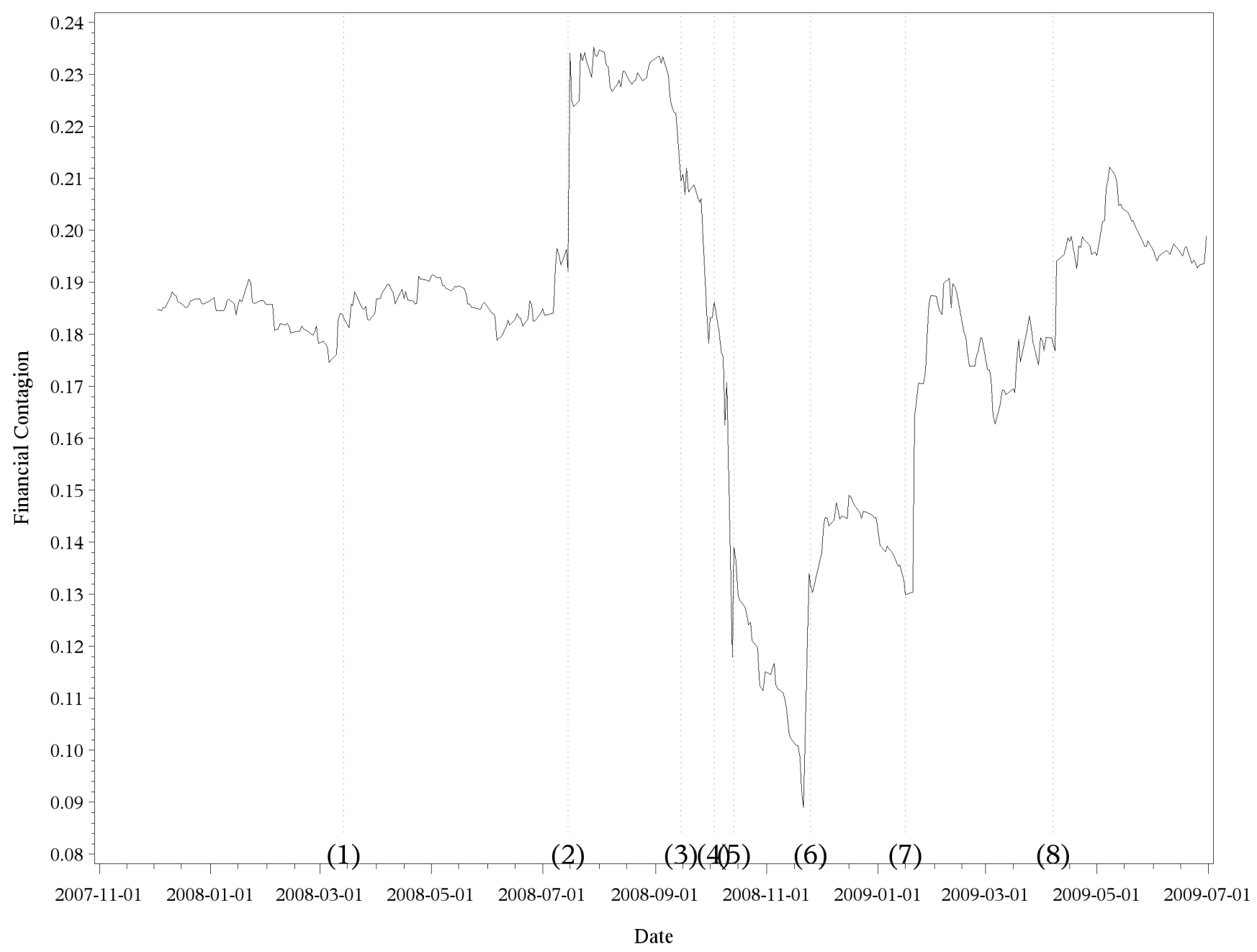

Figure 4 Financial Contagion in the 2007-2008 Crisis. This figure plots financial contagion around the time of the 2007-2008 financial crisis, annotated with key economic events. Events are labeled with numbers in parentheses at the bottom of the plot. (1) March 14, 2008: Bear Stearns is bailed out by the New York Federal Reserve and J.P. Morgan, (2) July 15, 2008: SEC emergency order to ban naked short selling in a number of large financial institutions, (3) September 15, 2008: Lehman Brothers files for chapter 11 bankruptcy protection; September 16, 2008: Federal Reserve extends an $\$ 85$ billion credit facility to American International Group (AIG), (4) October 03, 2008: The Emergency Economic Stabilization Act of 2008, containing the Troubled Asset Relief Program (TARP) is passed by Congress and signed by president Bush, (5) October 14, 2008: The U.S. Treasury announces the TARP program, (6) November 25, 2008: The Term Asset-Backed Securities Loan Facility (TALF) is announced, (7) January 16, 2009: The U.S. government announcement an agreement providing a package of guarantees, liquidity and capital to Bank of America, (8) April 07, 2009: Monthly TARP report is released. 


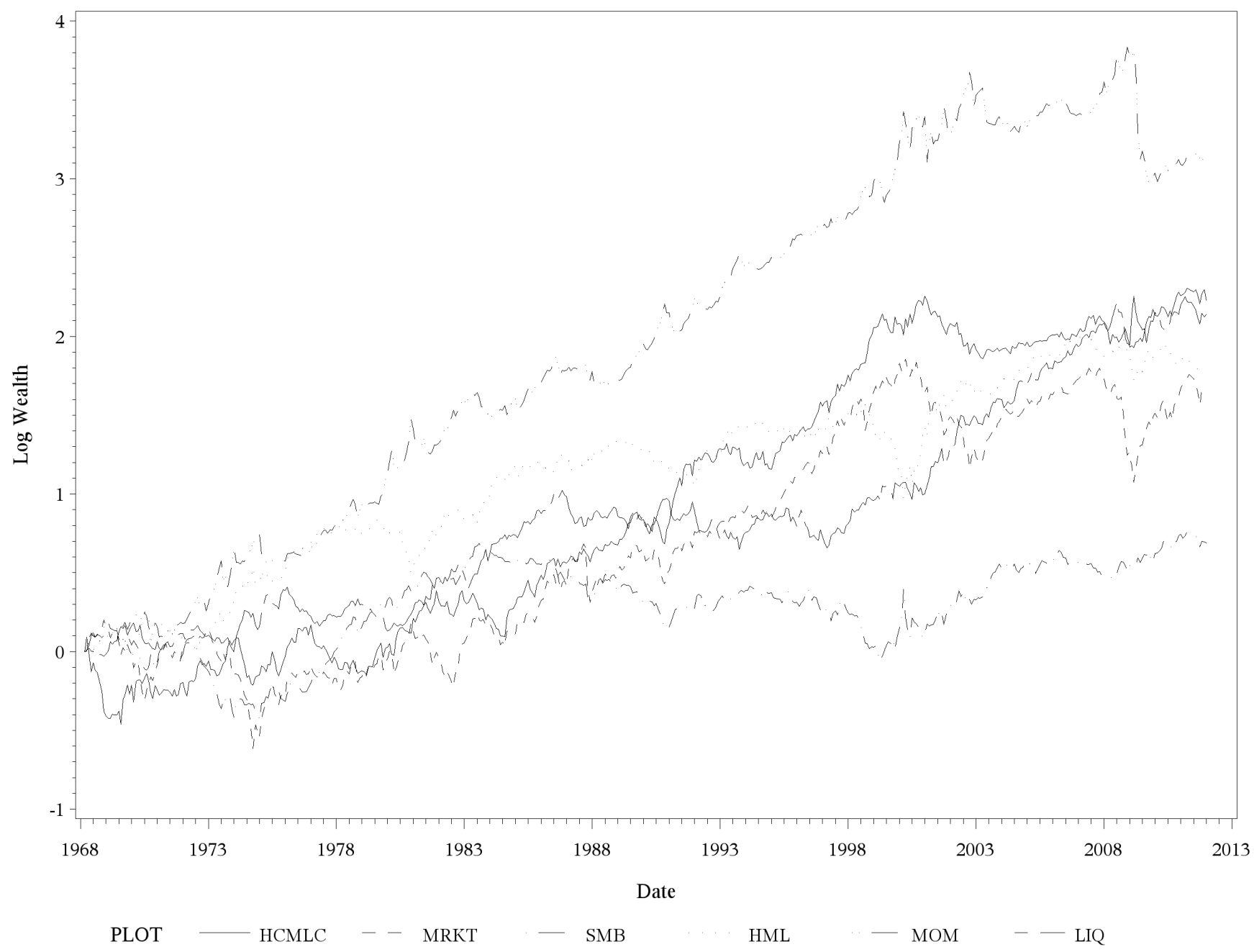

Figure 5 Log Wealth Processes. This figure plots the log wealth process for the portfolio that buys the decile of most contagious banks and sells the decile of least contagious banks, with monthly re-balancing. Log wealth processes of the MRKT, SMB, HML, MOM, and LIQ factor portfolios are also plotted. MRKT is the excess market return factor, SMB is the small minus big return factor, HML is the high minus low return factor, MOM is the momentum return factor, LIQ is the liquidity return factor, and HCMLC is the high contagion minus low contagion bank return factor. 


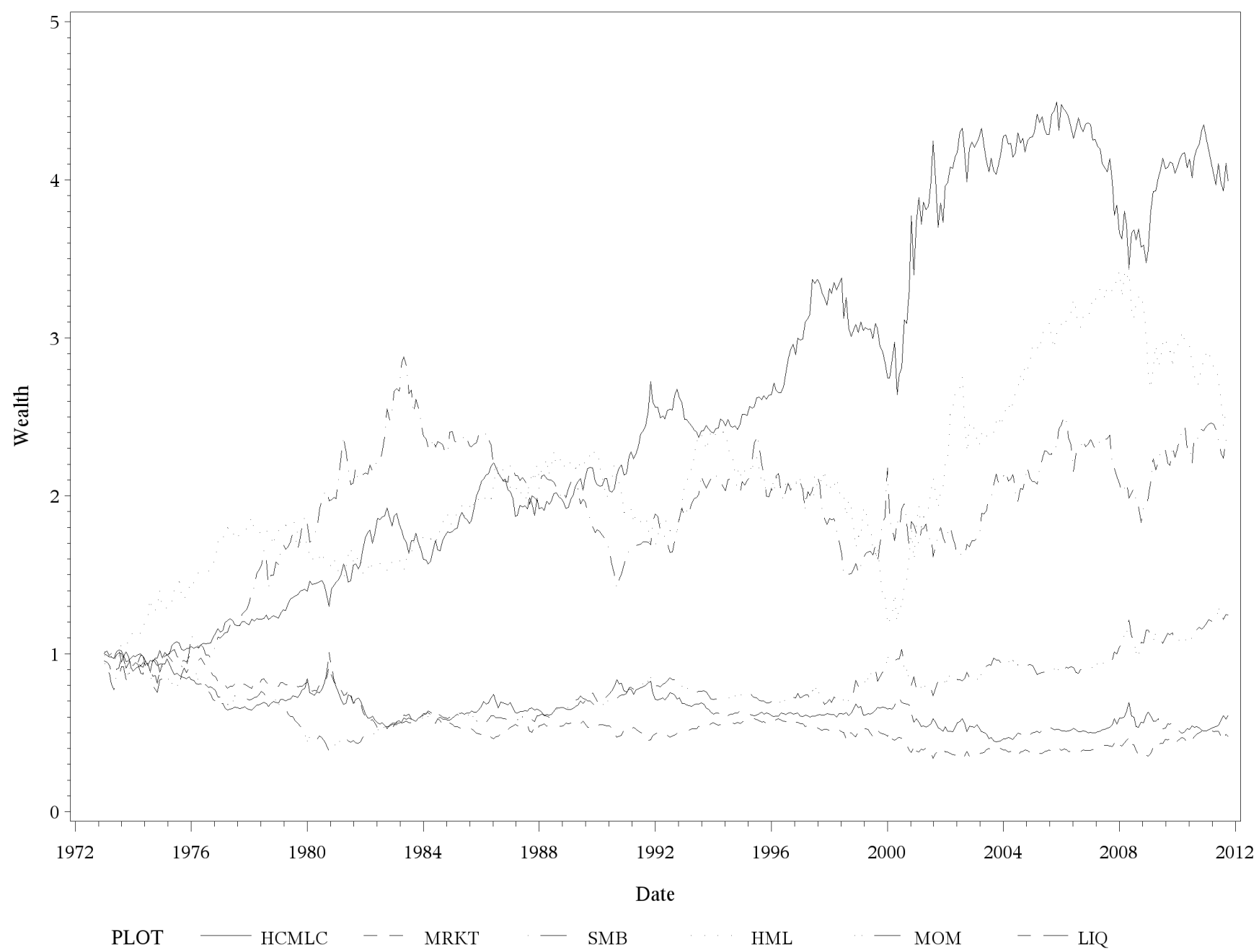

Figure 6 Beta-sorted Portfolio Wealth Processes. This figure plots the wealth processes of portfolios that buy the tercile of stocks with greatest factor beta and sell the tercile of stocks with lowest factor beta. Portfolios are rebalanced monthly. Factor betas are estimated from the following rolling regression.

$$
\begin{aligned}
r_{i, t}^{e}=\beta_{i, 0} & +\beta_{i, M R K T} r_{M R K T, t}+\beta_{i, S M B} r_{S M B, t}+\beta_{i, H M L} r_{H M L, t}+\beta_{i, M O M} r_{M O M, t} \\
& +\beta_{i, L I Q} r_{L I Q, t}+\beta_{i, H C M L C} r_{H C M L C, t}+\varepsilon_{i, t}
\end{aligned}
$$

Rolling 60-month regressions are estimated. The previous 60 months of returns are used to estimate betas, portfolios are rebalanced, and portfolio returns are observed in the following month. MRKT is the excess market return factor, $\mathrm{SMB}$ is the small minus big return factor, HML is the high minus low return factor, MOM is the momentum return factor, LIQ is the liquidity return factor, and HCMLC is the high contagion-minus-low contagion bank portfolio. 

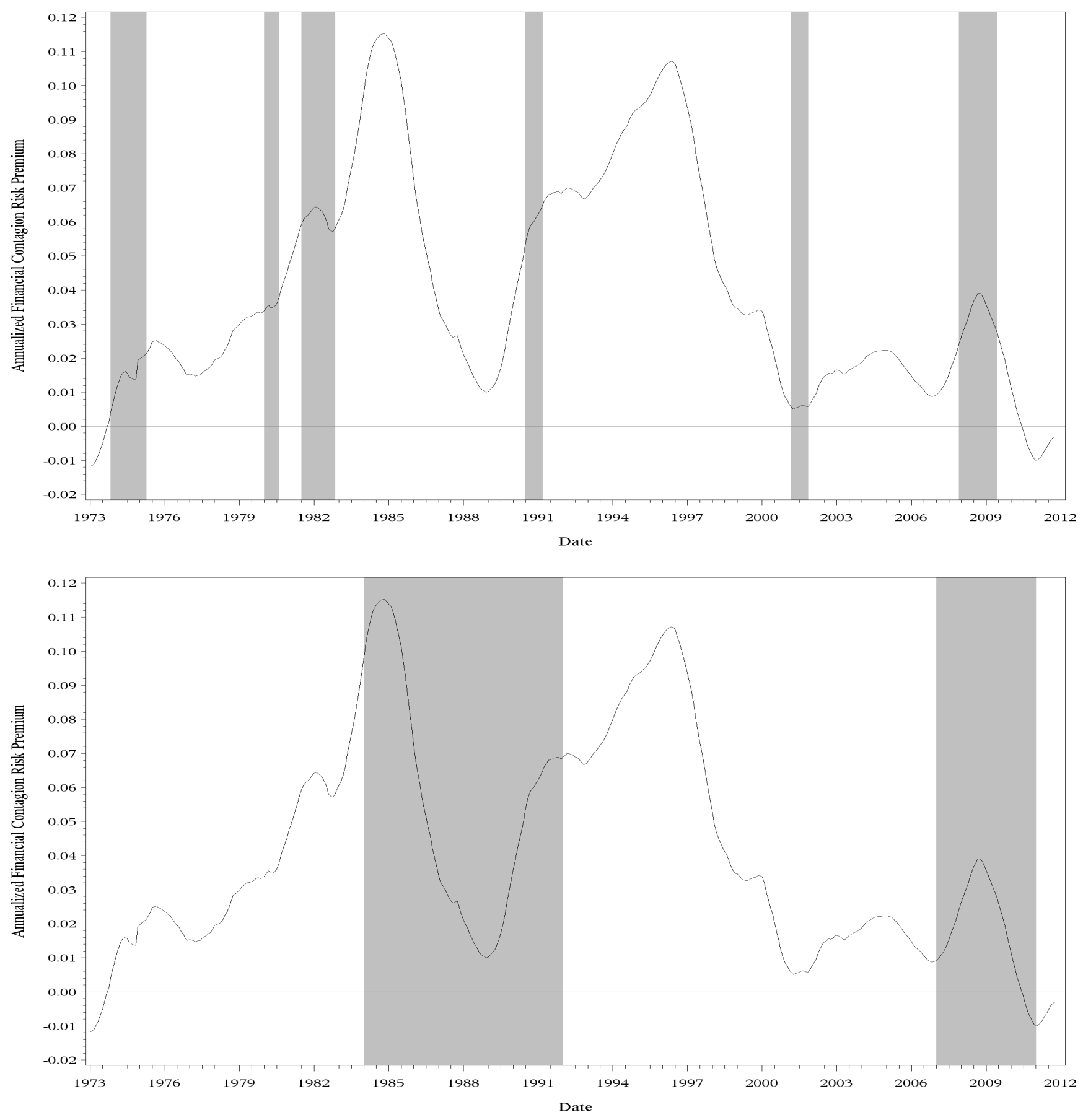

Figure 7 Time Series of Financial Contagion Risk Premium. This figure plots the smoothed time series of the estimated financial contagion risk premium, $\widehat{\lambda}_{H C M L C}$, obtained from firm-level Fama-MacBeth regressions as in Table VI. The shaded regions in the top panel are NBER recession dates and the shaded regions in the bottom panel are U.S. banking crises dates from Reinhart and Rogoff (2011). The smoothing procedure used is given by

$$
\widehat{\widehat{\lambda}}_{H C M L C}=\sum_{m=-h}^{h}\left[\frac{h+1-|m|}{(h+1)^{2}}\right] \widehat{\lambda}_{H C M L C}
$$

where $h=23$ (5 percent of the sample size) and the smoothing procedure is run twice. 